\title{
Dynamic Maneuver Loads Calculations for a Sailplane and Comparison with Flight Test
}

\author{
Arne Voß - Per Ohme
}

Received: date / Accepted: date

\begin{abstract}
This work presents the results of dynamic maneuver simulations of a sailplane and the comparison to flight test data. The goal of the effort is to extend and validate an in-house toolbox used for loads analysis of free-flying flexible aircraft in the time domain. The underlying aerodynamic theories are the steady Vortex Lattice and the Doublet Lattice Method with a rational function approximation (RFA) for the unsteady simulations in the time domain. The structural model comprises a beam model to represent the stiffness properties and a lumped mass model, both are developed using preliminary design methods. Steady aeroelastic trim simulations are performed and used as initial condition for the time simulation of the unsteady maneuvers in which the pilot's commands, which were recorded during flight test, are prescribed at the control surfaces. Two vertical maneuvers with elevator excitation, two rolling maneuvers with aileron excitation and three aileron sweeps are simulated. The validation focuses on the comparison of interesting quantities such as section loads, structural accelerations and the rigid body motion. Good agreement between simulation and flight test data is demonstrated for all three kinds of maneuvers, confirming the quality of the models developed by the preliminary design methods.
\end{abstract}

Arne Voss

DLR - German Aerospace Center

Institute of Aeroelasticity

Bunsenstraße 10

37073 Göttingen, Germany

E-mail: arne.voss@dlr.de

Per Ohme

DLR - German Aerospace Center

Institute of Flight Systems
Keywords dynamic maneuver loads · flight test . sailplane · preliminary design · aeroelasticity . structural dynamics

\section{Introduction}

DLR has a large number of activities in aircraft preliminary design $[22,29,52,53,17,28,34]$ and in the operation of a fleet of research aircraft [26,2], requiring in-depth expertise in loads analysis and modeling. The DLR project iLOADS [27] was started with the objective to improve the loads process in the DLR. The expertise in loads analysis is combined and integrated into a comprehensive loads process [23]. Such a process has been formally defined, and global rules for analysis and documentation have been set. Selected numerical methods for loads analysis have been evaluated, and the loads process has been used for investigating the influence of different analysis approaches on aircraft structural design [10]. Finally, the process is subject to verification and validation on different aircraft configurations, numerically as well as experimentally [46]. In this work, the simulation capabilities for dynamic flight maneuvers and resulting structural loads are tested and compared to flight test data from the DLR's Discus-2c sailplane [1]. For the simulation of the dynamic maneuver loads, the inhouse software Loads Kernel is selected. The Discus$2 \mathrm{c}$ is equipped with over a dozen strain gauges to measure the structural deformation and loads during flight. A flight test campaign has been prepared [36] and analyzed [32,38], by the DLR Institute of Flight Systems. Because the measurement equipment has been extensively calibrated, the results are expected to be reliable and are used for validation of the simulation. 
The mass and stiffness models of the Discus-2c used for the numerical simulations are built using simplified approaches from preliminary design methods.

This leads to the following three objectives for this work:

- Asses the applicability of simplified formulations (preliminary design) in the development of models for dynamic maneuver loads analyses

- Test the capabilities of the loads process for the simulation of dynamic maneuver loads in the time domain

- Validate simulation results against flight test data

Aeroelastic models of existing aircraft usually are proprietary of an aircraft company. In addition, only aircraft dedicated to flight testing are equipped with measurement systems. Few institutions operate such aircraft. These are probably the reasons why, to the authors' best knowledge, there are few publications concerning dynamic maneuver loads calculation including a comparison to flight test data. The works by Montel and Thielecke [30] involve empennage loads measurements of the ultra light aircraft UW-9 Sprint for the validation of a loads observer. Eller and Ringertz [13,14] performed flight tests with the ASK21 sailplane and focused on flight mechanical aspects, flutter and aeroservoelastics. Load tests of the Lockheed L-1011 TriStar, developed in the 1970s, were used for tool validation at Lockheed [39, 48,49]. Climent et al. [9] and Claverias et al. [8] present a wake vortex encounter of the A400M and compare numerical simulation to measured loads, demonstrating the capabilities of the tool-sets available at Airbus.

This paper presents an extension of a pervious work [54] and is organized as follows: In Sections 2 and 3, the set-up of the aeroelastic models (mass, stiffness, aerodynamic and coupling model) is presented. In Sections 4 and 5 the theoretical background of the selected methods is formulated. While the underlying aeroelastic models are unaltered in comparison to [54], significant work was put in the improvement of the simulation methods. Physically important effects, such as induced drag, have been identified and included in the simulation environment Loads Kernel. The methodical improvement result in more accurate simulation results, which is reflected in the comparison with flight test. Especially the simulation of the rolling maneuvers could be improved with respect to [54]. Section 6 briefly describes the measurement equipment and the procedure of the flight test campaign. The resulting data is compared to the simulation results in Section 7 . The results include longitudinal maneuvers and improved results for the rolling maneuvers. In addition, measurement data for more complex aileron sweep maneuvers is extracted and processed from the raw fligh test data. These maneuvers allow for a detailed comparison of the elastic properties of the aircraft. Based on the simulation results, the influence of unsteady aerodynamics is worked out in detail and the effect of a reduced control surface efficiency of the aileron is studied. In the last Section, a conclusion is drawn and an outlook on future work and on possible improvements is given.

\section{Preliminary Stiffness and Mass Models}

The stiffness and mass models for the loads analysis are developed with simple preliminary design methods. It is also an objective of this work to verify the applicability of such simplified formulations in the development of loads models for dynamic analyses. The verification with flight test data is in this case an important step in increasing confidence in such quick models for initial analysis.

The stiffness model is based on a beam model. The wing stiffness and mass distribution is estimated with the following process:

1. The wing lift during a pull-up maneuver is calculated and compared to the one of a quasi-static gust. The highest lift force is selected for structural sizing;

2. The wing lift distribution is calculated from the total lift by applying a distribution according to Schrenk [45];

3. The wing inertia distribution is proportional to the local chord squared times the airfoil thickness to chord ratio $c^{2} \cdot(t / c)$;

4. The wing shear force and bending moment along the span are integrated from the wingtip to the wing root;

5. The spar caps are sized according to the material allowable and the local bending moment. The spar webs are sized according to the material allowable and the local shear force. The torsion cell is sized according to the torsion loads. The final selected thicknesses correspond to the maximum from the sized thickness and minimum gauge requirements.

6. The stiffness properties are calculated analytically at each wing cross-section.

The fuselage stiffness model is estimated from the fuselage geometry and a minimum thickness requirement. The horizontal tailplane (HTP) stiffness is based on the wing stiffness and is scaled to reflect 


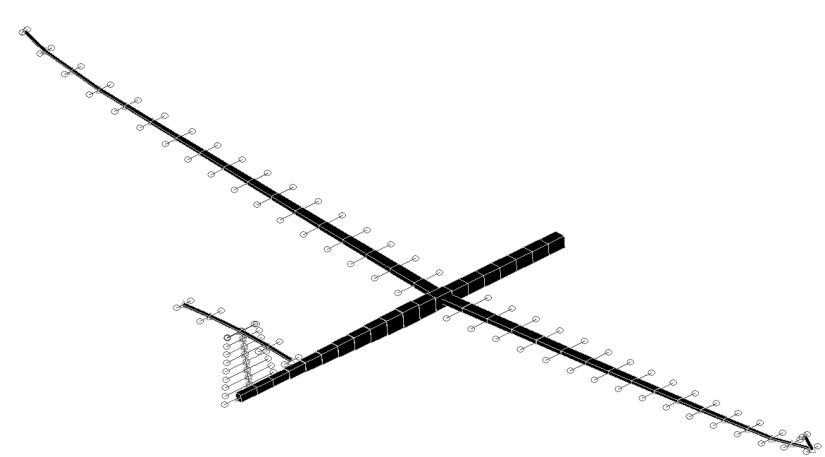

Fig. 1 Structural model of the Discus-2c

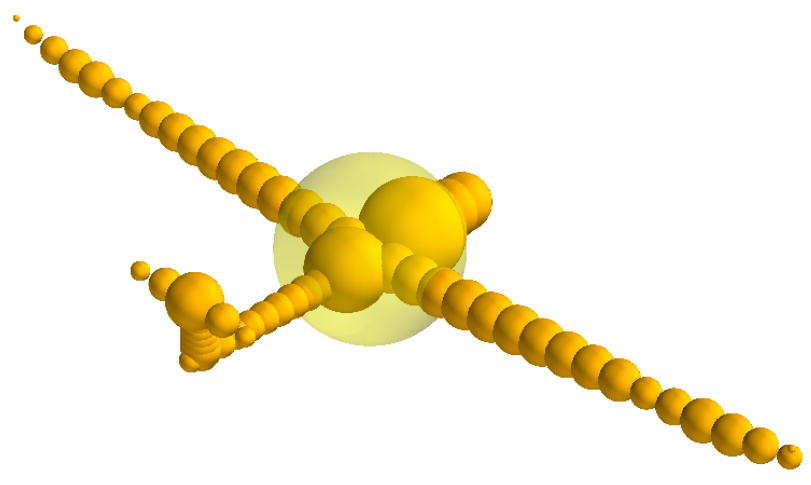

Fig. 2 Mass model of the Discus-2c

its size. The vertical tailplane (VTP) is assumed rigid. The final beam model is shown in Figure 1. The beam dimensions represent the stiffness properties.

The mass model is obtained by distributing the known masses of each component proportional to areas, volumes or concentrated as point masses. The fuselage mass is distributed proportional to the structural crosssection area. The wing, HTP and VTP masses are distributed proportional to $c^{2} \cdot(t / c)$. The center of gravity of the sections along the wing is at $45 \%$ of the local chord. A non-dimensional radius of gyration equal to 0.26 relative to the local chord is used to estimate the local pitching moment of inertia. Pilot and equipment masses are placed as concentrated point masses. The final mass model is shown in Figure 2. The spheres visualize the lumped mass distribution. The light, transparent sphere visualizes the total aircraft mass and is located at the center of gravity. Finally, a modal analysis is performed. The mode shapes and corresponding frequencies are compared to data obtained during a ground vibration test and show a satisfactory agreement.

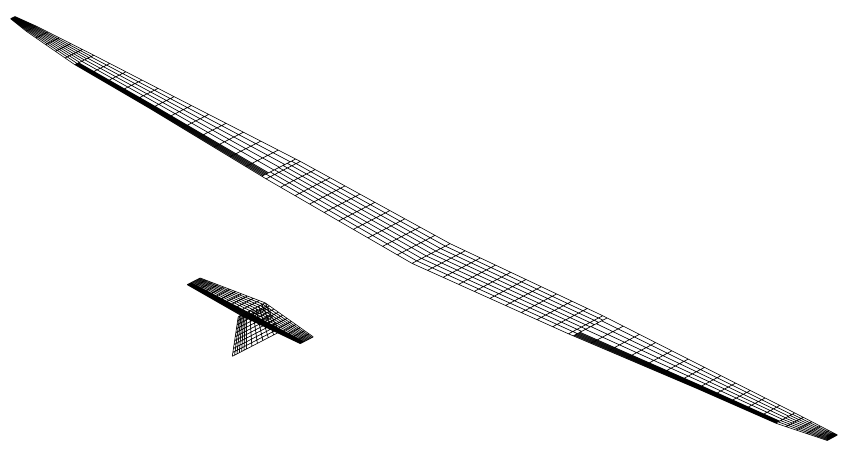

Fig. 3 Aerodynamic mesh of the Discus-2c

\section{Aerodynamic Model and Aero-Structural Coupling}

The classical aerodynamic approach with the steady Vortex Lattice Method (VLM) and the unsteady Doublet Lattice Method (DLM) is chosen. The formulation of the VLM follows closely the derivation given by Katz and Plotkin [20] using horse shoe vortices. The DLM is formulated as given by Rodden $[3,5]$. The implementation in Matlab is available from Kotikalpudi $[24,25]$ and was slightly adapted to respect the dihedral of the wings. In addition, the PrandtlGlauert Transformation with $\beta=\sqrt{\left(1-M a^{2}\right)}$ is applied to the VLM as suggested by Hedman [18]. The VLM and the DLM are based on a matrix of aerodynamic influence coefficients (AIC), which depends on the Mach number $M a$ and reduced frequency $k$ defined in Equation 2. With $k=0$ for the quasi static case, the solution of the DLM is equivalent to the VLM [42]. The AIC matrix relates an induced downwash $w_{j}$ on each aerodynamic panel to a complex pressure coefficient $c_{p}$ given by

$\Delta c_{p}=A I C(M a, k) \cdot w_{j}$

with

$k=\frac{c_{\mathrm{ref}} / 2}{U_{\infty}} \cdot \omega$.

The aerodynamic mesh used for the Discus-2c is shown in Figure 3. Camber and twist of the wing is not included.

The calculation of the steady aerodynamic forces is given by

$$
\begin{aligned}
P_{k}^{\text {aero,steady }}= & q_{\infty} S_{k j} A I C^{\text {steady }}\left(D_{j r b m} u_{r b m}+D_{j c s} u_{c s}\right. \\
& \left.+D_{j k}^{1} T_{k g} \Phi_{g f} u_{f}+D_{j k}^{2} T_{k g} \Phi_{g f} \dot{u}_{f}\right) \frac{1}{U_{\infty}}
\end{aligned}
$$

(Ref. [41]), containing several sources of aerodynamic forces. 
$q_{\infty} \quad$ dynamic pressure

$S_{k j} \quad$ aerodynamic integration matrix

$A I C \quad$ AIC-matrix

$D_{\text {jrbm }}$ differential matrix of rigid body motion

$D_{j c s} \quad$ differential matrix control surface deflections

$D_{j k}^{1} \quad$ differential matrix of deformation

$D_{j k}^{2} \quad$ differential matrix of velocity

$u_{r b m}$ rigid body motion

$u_{c s} \quad$ control surface deflections

$u_{f} \quad$ flexible structural deformation

$\dot{u}_{f} \quad$ flexible structural motion

$T_{k g} \quad$ spline matrix for aero-structural coupling

$\Phi_{g f} \quad$ modal matrix of flexible structural modes

$U_{\infty} \quad$ free stream velocity, equal to flight velocity

Forces by rigid body motions are given by the term $D_{j r b m} u_{r b m}$ and control surface deflections are considered in $D_{j c s} u_{c s}$. Structural flexibility is incorporated in the two terms $D_{j k}^{1} T_{k g} \Phi_{g f} u_{f}$ and $D_{j k}^{2} T_{k g} \Phi_{g f} \dot{u}_{f}$ for the structural deformation and motion respectively. Using an AIC-matrix approach leads to a local pressure distribution which is integrated and translated to the structural grid using matrices $S_{k j}$ and $T_{k g}$. As the AIC-matrix is normalized with the dynamic pressure $q_{\infty}$, the resulting loads need to be multiplied with $q_{\infty}$ to obtain forces and moments. In this implementation, forces from the different sources given in Equation 3 are calculated independently and superimposed

$P_{k}^{\text {aero,steady }}=P_{k}^{\text {aero,rbm }}+P_{k}^{\text {aero,cs }}+P_{k}^{\text {aero,flex }}$.

Drag is neglected by most commercial software packages for loads analysis and is assumed to have little direct influence on the loads. In addition, wing structures are typically sized by $F_{\mathrm{z}}, M_{\mathrm{x}}$ or $M_{\mathrm{y}}$. However, the local induced drag is important to capture the roll-yaw-coupling of the aircraft. Note that there are also other contributors to the roll-yaw-coupling, e.g. profile drag, which is not considered at this point. A good prediction of the aircraft motion is necessary to calculate the resulting loads appropriately, e.g. for rolling maneuvers as performed during flight test. Thus, the induced drag will have an indirect influence on the loads. Therefore, the VLM is extended. The procedure described above involves a linearization about an angle of attack $\alpha=0^{\circ}$, resulting in a lift vector orthogonal to the body frame but not orthogonal to the onflow for angles of attack $\alpha \neq 0^{\circ}$. This would result in an artificial drag component depending on the angle of attack $\alpha$, which is not desired. This can be avoided by selecting a slightly different formulation of the VLM, given by

$P_{k}^{\text {aero,steady,nonlin }}=\Phi_{l k} \rho \Gamma w_{j}(q \times r)$.
The induced downwash $w_{j}$ on each aerodynamic panel is multiplied with the circulation matrix $\Gamma$ obtained from the VLM. The cross product of the onflow vector $q$ and the panel span vector $r$ at quarter chord yield a lift vector orthogonal to the onflow condition. Multiplication with the air density $\rho$ and translation matrix $\Phi_{l k}$ gives the aerodynamic forces $P_{k}^{\text {aero,steady,nonlin }}$. The induced downwash $w_{j}$ is calculated in the same way as before, allowing for a smooth integration into existing codes.

In a flow field, the Trefftz plane located at an infinite distance downstream of the aircraft may be used to analyze the wake in order to obtain the total induced $\operatorname{drag} C_{d}^{\text {ind }}$. In a similar manner, the wake of every panel, defined by the trailing vortices of the horseshoe, may be used to calculate the local induced $\operatorname{drag} c_{d j}^{\text {induced at every }}$ panel. Formally, this can be expressed with matrix $B_{j j}$ using

$c_{d j}^{\text {ind }}=w_{j}^{\text {wake }} \cdot c_{p j} \quad$ and $\quad w_{j}^{\text {wake }}=-B_{j j} \cdot c_{p j}$.

The calculated induced drag can be compared to the theoretically lowest induced drag for planar wings based on an elliptical lift distribution. Division of theoretical and calculated induced drag yields the span efficiency value $e$ :

$e=\frac{C_{l}^{2}}{\pi \Lambda C_{d}^{\text {ind }}}$.

As the Discus-2c is a rather efficient sailplane, $e$ is expected to be close to 1.0. Actually, $e$ turned out to be slightly larger due to the non-planar winglets and the definition of the aspect ratio $\Lambda$. Finally, to achieve a plausible lift-to-drag ratio $L / D$, additional drag $C_{d}^{\text {add }}$ is introduced by

$C_{d}^{\text {add }}=C_{d 0}+k \cdot C_{l}^{2}$.

The lift-to-drag ratio is important to get a plausible vertical speed $w$ in the initial trim calculation and during the time simulation. Values for $C_{d 0}$ and $k$ are estimated from other aircraft to account for drag from skin friction and pressure drag.

Unsteady aerodynamic forces in the time domain are obtained by a rational function approximation (RFA) as suggested by Roger [43] and are added to the steady aerodynamic forces

$P_{k}^{\text {aero }}=P_{k}^{\text {aero,steady }}+P_{k}^{\text {aero, unsteady }}$.

The implementation is based on the work of Gupta [16], Kier and Looye [21] and Karpel and Strul [19]. A difference is the approximation on panel level using 
physical coordinates. This leads to a large number of lag states but the implementation is more generic and leads to physical, nodal forces. This is desirable in order to use the Force Summation Method, which will be explained in Section 4. A rational function approximation allows for a decomposition of the aerodynamic forces

$$
\begin{gathered}
P_{k}^{\text {aero }}(t)=q_{\infty} \cdot\left[A_{0} w_{j}+A_{1}\left(\frac{c_{\text {ref }}}{2 V}\right) \dot{w}_{j}+A_{2}\left(\frac{c_{\text {ref }}}{2 V}\right)^{2} \ddot{w}_{j}\right. \\
\left.+A_{3} \cdot \operatorname{lag}_{1}+A_{4} \cdot \operatorname{lag}_{2}+\ldots+A_{n+2} \cdot \operatorname{lag}_{n}\right], \quad(10)
\end{gathered}
$$

into a steady term $A_{0}$ depending on the downwash $w_{j}$ corresponding to Equation 3, a damping term $A_{1}$ depending on the change rate of the downwash $\dot{w}_{j}$ and a term $A_{2}$ depending on the acceleration of the downwash $\ddot{w}_{j}$. However, matrix $A_{2}$ is omitted during the approximation, as suggested by Kier and Looye [21]. The unsteady terms $A_{3}, A_{4}, \ldots, A_{n+2}$ depend on the lag states $\operatorname{lag}_{1}, \operatorname{lag}_{2}, \ldots, \operatorname{lag}_{n}$. As the time simulation usually starts from an initial steady level flight, the lag states are assumed to be zero at the beginning. The lag state derivatives $\dot{l a g}_{i}$ are given by

$l \dot{a} g_{i}=\dot{w}_{j}-\left(\frac{2 V}{c_{\text {ref }}}\right) \cdot \beta_{i} \cdot l a g_{i}$.

In this work, the poles $\beta_{i}$ used for the approximation are determined by

$\beta_{i}=\frac{k_{\max }}{i}$,

as given by Roger [43]. A slightly different proposal is given by ZONA [57]. Both methods were tested and showed comparable results. The quality of the approximation has to be checked carefully, because too few poles result in a bad approximation, leading to nonphysical results. For the Discus-2c, the selected number of poles is $n_{\text {poles }}=9$ for the highest reduced frequency, $k_{\max }=4.0$.

The fuselage effect on the longitudinal aerodynamic properties is estimated as an additional pitching moment derivative due to the angle of attack $d C m / d \alpha$. The method from Truckenbrodt and Schlichting [44] is used for this approach. It consists of calculating the pitching moment characteristics of a slender body under influence of a straight wing within the limitations of potential aerodynamics. The fuselage contribution to the yawing moment due to sideslip $d C n / d \beta$ is estimated with handbook methods based on the slender-body theory [31]. The contribution of the fuselage is nevertheless small for both coefficients.

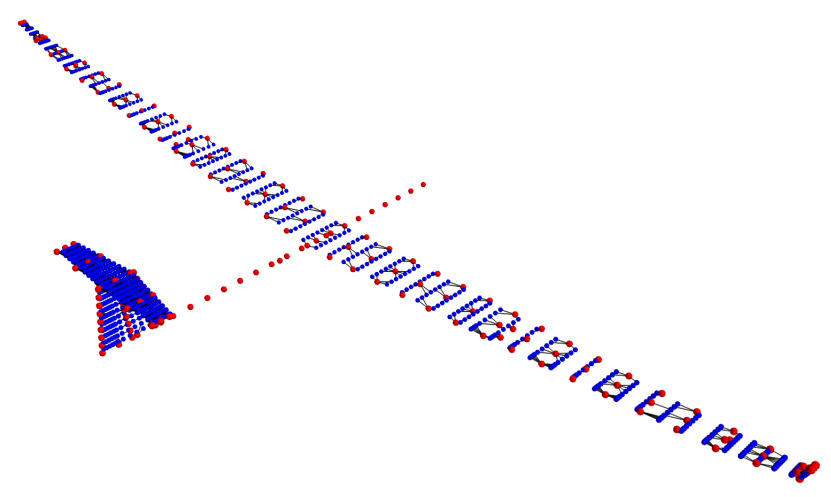

Fig. 4 Coupling of the aerodynamic panel center points (blue) to the structural points (red) with a rigid body spline

The aerodynamic forces and moments are calculated on the aerodynamic grid. The structural grid might be of much higher or lower discretization and in some cases, local coordinate systems might be used. This is one typical example where forces and moments need to be transferred from one grid to another. In addition, structural deflections need to be transferred back onto the aerodynamic grid. These operations can be handled with using the transformation matrix $T_{d i}$ which relates displacements of an independent grid $u_{i}$ to displacements of a dependent grid $u_{d}$ :

$u_{d}=T_{d i} \cdot u_{i}$

In addition, the transposed matrix $T_{d i}^{T}$ transforms forces and moments from a dependent grid $P_{d}$ to an independent grid $P_{i}$ :

$P_{i}=T_{d i}^{T} \cdot P_{d}$

The transformation matrix $T_{d i}$ may be defined by various methods. One commonly used approach for loads calculation is the rigid body spline. Each grid point of the dependent grid is mapped to exactly one point on the independent grid. The connection between these two grid points is assumed as a rigid body that transfers forces and moments. In addition, forces $F$ create moments $M$ due to their lever arm $r$ :

$M=r \times F$.

In reverse, translations and rotations are directly transferred and rotations create additional translations. The mapping of the points may be defined manually or automatically, e.g. with a nearest neighbor search. As this concept is quite fast and versatile, it is selected for the aero-structural coupling in this work. The coupling model is shown in Figure 4. The small black lines between the blue and red dots visualize the mapping. 


\section{Equation of Motion and Loads Recovery}

The motion of the aircraft is divided into a rigid and a flexible part. For the rigid body motion, the aircraft is considered as a point mass with inertia matrices $M_{b}$ and $I_{b}$, where the components of the inertia tensor $I_{b}$ are calculated with respect to the body axes $b$. Its origin is positioned at the center of gravity. All external forces and moments $P_{b}^{\text {ext }}$ are gathered at the same point. The non-linear equations of motion are given by

$\dot{V}_{b}=M_{b}^{-1} \cdot P_{b}^{\text {ext, forces }}+V_{b} \times \Omega_{b}+\dot{V}_{b}^{\text {grav }}$

and

$\dot{\Omega}_{b}=I_{b}^{-1} \cdot\left(P_{b}^{\mathrm{ext}, \text { moments }}-\Omega_{b} \times\left(I_{b} \cdot \Omega_{b}\right)\right)$,

yielding the translational and rotational accelerations $\dot{V}_{b}$ and $\dot{\Omega}_{b}$ of the aircraft body frame. The coupling terms between translation and rotation $V_{b} \times \Omega_{b}$ and $\Omega_{b} \times$ $\left(I_{b} \cdot \Omega_{b}\right)$ are derived by Waszak, Schmidt and Buttrill $[7,55,56]$. Gravitational acceleration is accounted for by $\dot{V}_{b}^{\text {grav }}$ in Equation 16.

In addition to the rigid body motion of the aircraft, linear structural dynamics are incorporated by

$M_{f f} \ddot{u}_{f}+D_{f f} \dot{u}_{f}+K_{f f} u_{f}=P_{f}^{\mathrm{ext}}$.

Here, generalized external forces $P_{f}^{\text {ext }}$ interact with linear elastic deflections $u_{f}$, velocities $\dot{u}_{f}$ and accelerations $\ddot{u}_{f}$. The matrices $M_{f f}, D_{f f}$ and $K_{f f}$ refer to the generalized mass, damping, and stiffness matrices. A modal damping of $2 \%$ is assumed.

The resulting nodal loads acting on the aircraft structure may be calculated by two different methods, the Mode Displacement Method [4] and the Force Summation Method [40]. The convergence of the Mode Displacement Method (MDM), given by

$P_{g}=K_{g} \cdot u_{g}=K_{g} \cdot \Phi_{f g} \cdot u_{f}$

strongly depends on the number of modes considered for the modal deformation vector $u_{f}$. The more modes are used, the more precise is the result. Using all modes, both methods should lead to identical results. With the Force Summation Method (FSM), given by

$P_{g}=P_{g}^{\text {ext }}+P_{g}^{\text {iner }}$,

the calculation is done using physical coordinates and the sum of inertia and external forces leads to the loads that are carried by the structure. In this work, the Force Summation Method is selected.

From these nodal loads, so-called interesting quantities are calculated. Interesting quantities usually include cutting forces and moments at various stations (e.g. along the wing) and attachment loads (e.g.

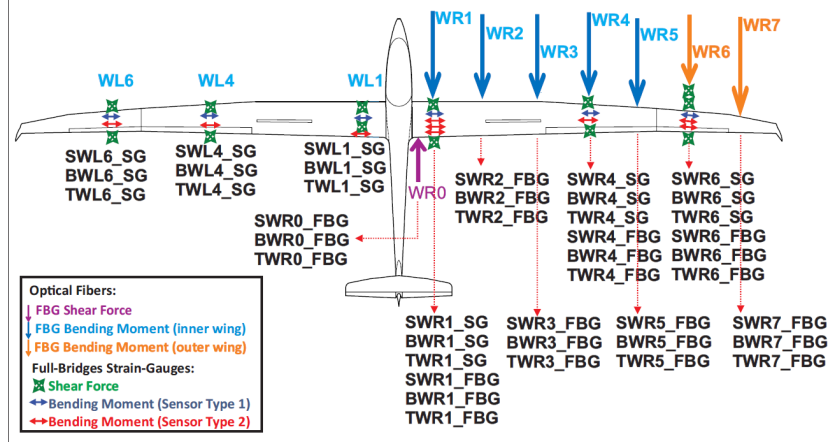

Fig. 5 Measured internal forces and moments (shear, bending, torque) and positions

from control surfaces, payload, landing gear, etc.). These quantities are calculated at so-called monitoring stations. For the Discus-2c sailplane, monitoring stations along the wing (WR1, WR2, ...) and the horizontal tail plane are defined in such a way that they are near the actual positions of the strain gauges. The positions of the monitoring stations are shown in Figure 5 whereas $\mathrm{S}, \mathrm{B}$ and $\mathrm{T}$ stand for shear, bending and torque, BWR4_SG means for example Bending-Moment-Wing-Right-Position4StrainGauge. The equations for calculating the internal forces and moments (shear, bending, torque) from the strain gauge measurements were developed by an extensive calibration program [36] and using the classical Skopinki method [47]. Additional optical strain sensors (Fiber-Bragg-Gratings, FBG) are installed inside the right wing but were not used. In addition, structural grid points are placed at the locations of the accelerations sensors used during testing. They have no mass properties and are attached directly to the primary structure to be used as "numerical accelerometers".

\section{Solution of the Trim Problem and Time Domain Simulation}

The calculation of aerodynamic forces and the evaluation of the equation of motion described in the previous Sections are cast into a single set of coupled equations. For the solution of this system, it is convenient to convert the equations into a first order system:

$\left(\begin{array}{c}\dot{u}_{i} \\ \ddot{u}_{b} \\ \dot{u}_{f} \\ \ddot{u}_{f} \\ \dot{u}_{c s}\end{array}\right)=f\left(\begin{array}{c}u_{i} \\ \dot{u}_{b} \\ u_{f} \\ \dot{u}_{f} \\ u_{c s}\end{array}\right)$. 
In a next step, the trim conditions are defined. The vector $u_{i}$ contains the aircraft position and Euler angles $(x, y, z, \Phi, \Theta, \Psi)^{T}$ with respect to the earthfixed frame 'i', vector $\dot{u}_{i}$ the aircraft velocities and rates $(\dot{x}, \dot{y}, \dot{z}, \dot{\Phi}, \dot{\Theta}, \dot{\Psi})^{T}$. The vector $\dot{u}_{b}$ contains the aircraft velocities and rates $(u, v, w, p, q, r)^{T}$ in the body-fixed frame 'b', vector $\ddot{u}_{i}$ the aircraft translational and rotational accelerations $(\dot{u}, \dot{v}, \dot{w}, \dot{p}, \dot{q}, \dot{r})^{T}$. Vector $u_{c s}$ contains the control commands about $x, y$ and $z$ axis $(\xi, \eta, \zeta)^{T}$. The trim conditions need to be set in such a way that they are not over- or underdetermined in order to calculate one unique solution of the equations. The Discus-2c sailplane is assumed in a steady descending flight at a given velocity $u$ before the maneuver starts. This requires the roll, pitch and yaw rates $\dot{p}, \dot{q}, \dot{r}$ to be zero while the control surface deflections $\xi, \eta, \zeta$ are flagged as free. In addition, $\dot{u}$ has to be zero so that the aircraft may not accelerate in horizontal direction. In exchange, a vertical velocity $w$ is allowed. The equations are then solved with Powell's non-linear root-finding algorithm $[15,35,51]$. Once this initial flight condition is found, a time simulation is started.

The time simulation is performed by an integration of Equation 21 over a period of time. Two different integration schemes have been tested. The explicit runge-kutta method of $4 \mathrm{th} / 5$ th order [11] and an implicit Adams-Bashforth method [6], both implemented in scipy [50], have shown numerically equivalent results. Because of the fewer function evaluations, the Adams-Bashforth method was selected. During the integration, the rate of change of the control surface deflections $\dot{u}_{c s}$ is fed into the simulation. The rate of change is calculated numerically from the control surface deflections $u_{c s}$ recorded during flight test using a backward differences quotient of first order.

One key element of the simulation is the feedback of the aircraft speed. In Figure 6, the loss of altitude during a longitudinal maneuver is shown. Within four seconds of time, the aircraft looses about 20 meters of altitude. Such a sink rate is very high for a normal sailplane and results in a gain of true airspeed $V_{\text {tas }}$ of about three meters per second. Assuming constant air density, the dynamic pressure $q_{\infty}=\rho / 2 \cdot V_{\text {tas }}^{2}$ is increased by $\approx 18 \%$, causing more lift so that the sailplane would return automatically into a normal, horizontal flight condition. Most commercial software packages assume a constant dynamic pressure, which would lead to an unphysical, diverging behavior of the aircraft.

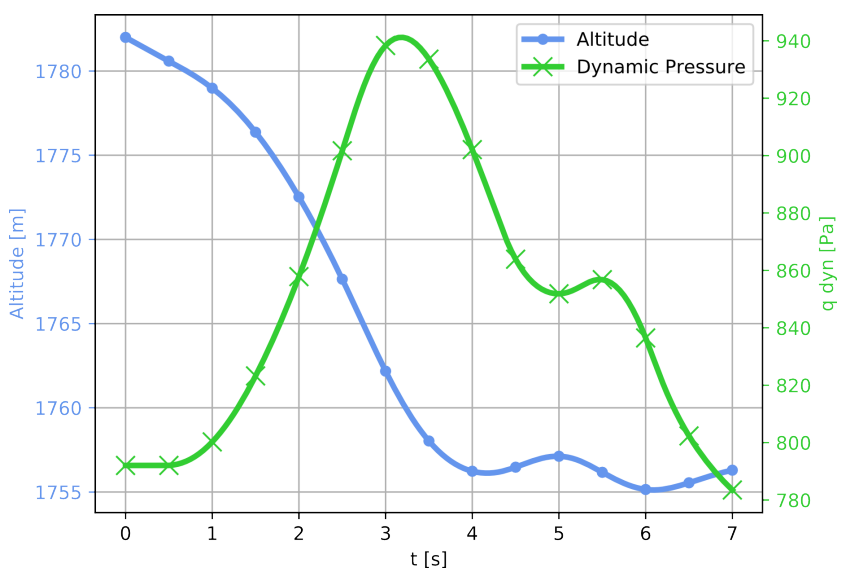

Fig. 6 Loss of altitude and gain of dynamic pressure during a longitudinal maneuver

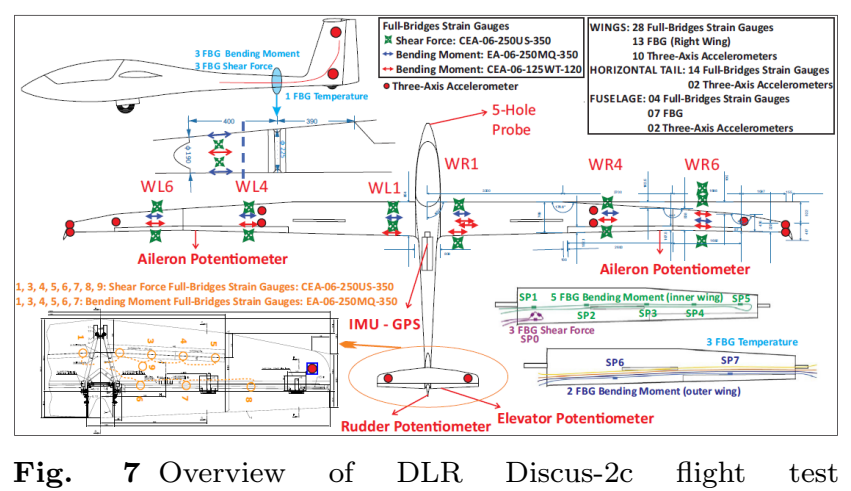

Fig. $\quad 7$ Overvien

\section{Flight Test and Loads Measurements of the Discus-2c}

The DLR Discus-2c is equipped with a complex flight test instrumentation which provides the possibility of measuring loads and accelerations at different parts of the aircraft structure. Therefore, strain gauges, Fiber-Bragg-Gratings and 3-axis accelerometers were already installed inside the aircraft structure during manufacturing. The main flight test data acquisition system is installed in the engine compartment where also a high precision inertial measurement unit (IMU) is located. Angles of attack and sideslip are measured by a 5-hole probe installed on a nose boom. For recording the control surface deflections, potentiometers are used. Figure 7 gives an overview of all installed sensors. The strain gauges are interconnected as full bridges so that thermal strains are canceled out. Overall, 46 strain gauge full bridges and 14 3-axis accelerometers are placed in wing, horizontal tail and fuselage. All measurements are recorded with a sample rate of $100 \mathrm{~Hz}$. As mentioned in Section 4, an extensive experimental test program was conducted to calibrate the sensor signals obtaining the internal loads at certain 


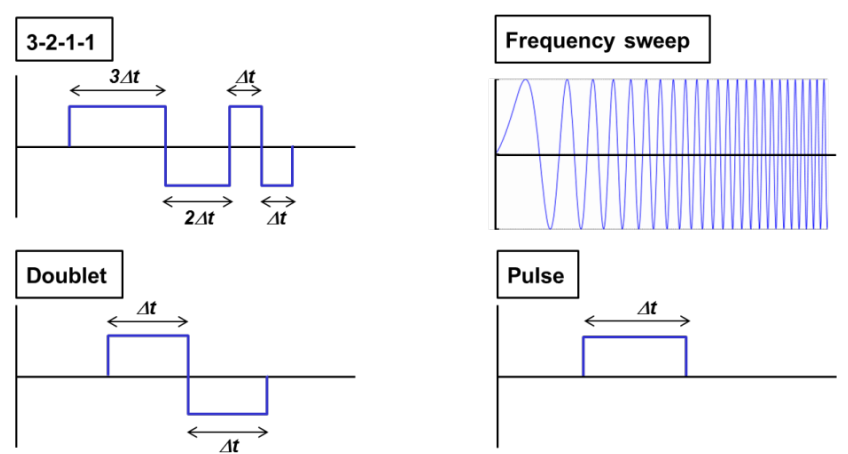

Fig. 8 Typical control surface inputs for system identification and loads analysis

positions $[37,47,32]$. In addition to the strain and acceleration sensors, the following measurements were recorded during flight test:

- static and dynamic pressure

- indicated and true airspeed (IAS, TAS)

- barometric altitude

- vertical speed based on barometric altitude

- static temperature

- angle of attack $\alpha$ and sideslip $\beta$ (uncalibrated)

- ground and vertical speed

- GPS position

- accelerations $A c c_{x, y, z}$ and rotational speeds $p, q, r$ (IMU)

- euler angles $\Phi, \Theta, \Psi$ (IMU)

- control surface deflections of ailerons $\xi$, elevator $\eta$, rudder $\zeta$ and airbrakes

During the flight test campaign, an overall of 22 flights including 396 maneuvers in longitudinal and lateral motion were conducted at different test points (altitude and speed). Figure 8 shows typical control surface inputs for excitation of rigid body and flexible modes. The sailplane was towed up to an altitude of $3000 \mathrm{~m}$. Selected test points were placed during descent at different speeds of 100, 130 and $160 \mathrm{~km} / \mathrm{h}$. For checking the recorded data quality directly after flight, a special software was developed which allows for an evaluation of the pilot inputs as well as finding inconsistencies in the data recording (sensor failures, dropouts, etc.).

\section{Comparison of Results}

In the following, the rigid body motion, section forces and structural accelerations from the numerical simulation are compared to the data obtained during flight test. Two longitudinal maneuvers with a 3-21-1 elevator input and two rolling maneuvers with aileron input are calculated. The rolling maneuvers turned out to be more difficult. One reason for this is that loads due to longitudinal maneuvers are high while the aircraft motion is small. This is different for the rolling maneuvers, where for example the bank angle is very high while the loads are lower. The aerodynamics due to the rolling and lateral motion are more difficult to capture than due to longitudinal motion. Finally, three maneuvers with an aileron excitation are calculated. The ailerons have small and short deflections with an increasing frequency (frequency sweep). The loads are much lower but structural dynamics and unsteady aerodynamics are more important. Therefore, these maneuvers are a challenge for both the aeroelastic models and the simulation environment. In the following, exemplary results for the longitudinal maneuvers, the rolling maneuvers and the aileron sweeps are shown and discussed.

\subsection{Longitudinal Maneuvers}

The rigid body motion during the longitudinal maneuvers are compared using the aircraft acceleration in $z$ direction, the euler angle $\Theta$ and the pitch rate $q$. They are shown in Figures 9, 10 and 11. The agreement is very good, even towards the end of the simulation time. For this kind of flight maneuver, the pilot's elevator input $\eta$ is the primary control command. In addition, the aileron input $\xi$ is included in the simulation, because it might cause additional aerodynamic forces. The drawback is clearly visible when looking at the role rate $p$ in Figure 11. During the flight, the sailplane is subject to atmospheric turbulence and the sailplane experiences a slight rolling motion, which the pilot tries to compensate, e.g. between 3.5 and 4.5 seconds or between 5.0 and 6.5 seconds. In Figure 12, the section loads at the right wing root are shown. Both the shear forces $F_{\mathrm{z}}$ and the bending moments $M_{\mathrm{x}}$ show a very good agreement with a slight underestimation compared to the measurements around 5.0 seconds. The outer wing shear forces $F_{\mathrm{z}}$ and the bending moments $M_{\mathrm{x}}$ shown in Figure 13 have a similar shape with a lower amplitude. Looking at the shear forces $F_{\mathrm{z}}$ and the bending moments $M_{\mathrm{x}}$ at the horizontal tail plane shown in Figure 14, one can see several pronounced peaks each time the pilot changes the elevator deflection. Once the aircraft starts to pitch (compare pitch rate in Figure 11), the loads on the horizontal tail are reduced. Figure 11 shows the acceleration in $z$ direction of the right wing tip. Although the measurement data is scattered, there is a very good agreement with the simulation. Even small, minor peaks occurring e.g. around 2.8, 4.5, 5.5 and 6.3 


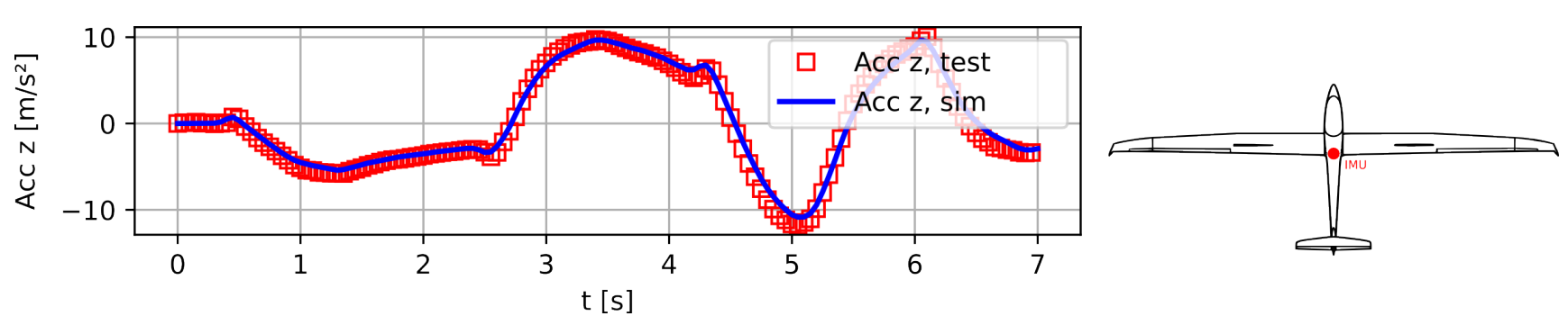

Fig. 9 Comparison of rigid body acceleration in $z$ direction
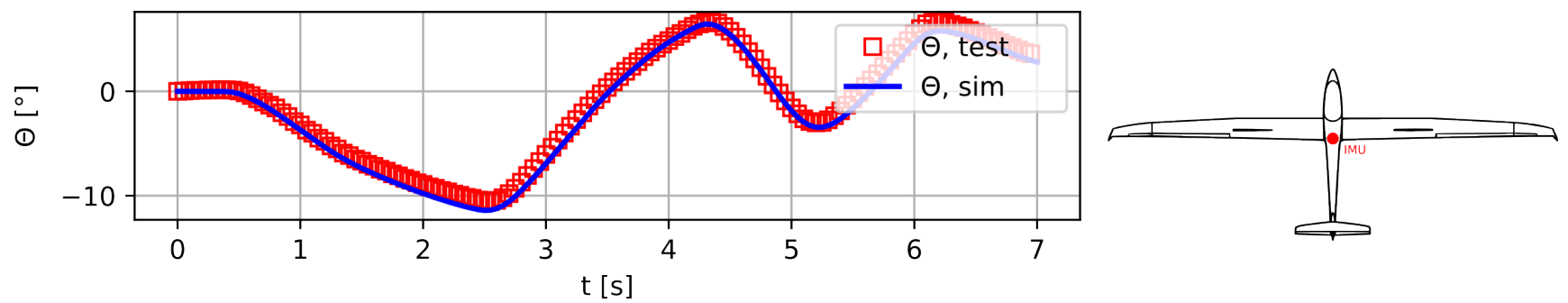

Fig. 10 Comparison of pitch angle $\Theta$
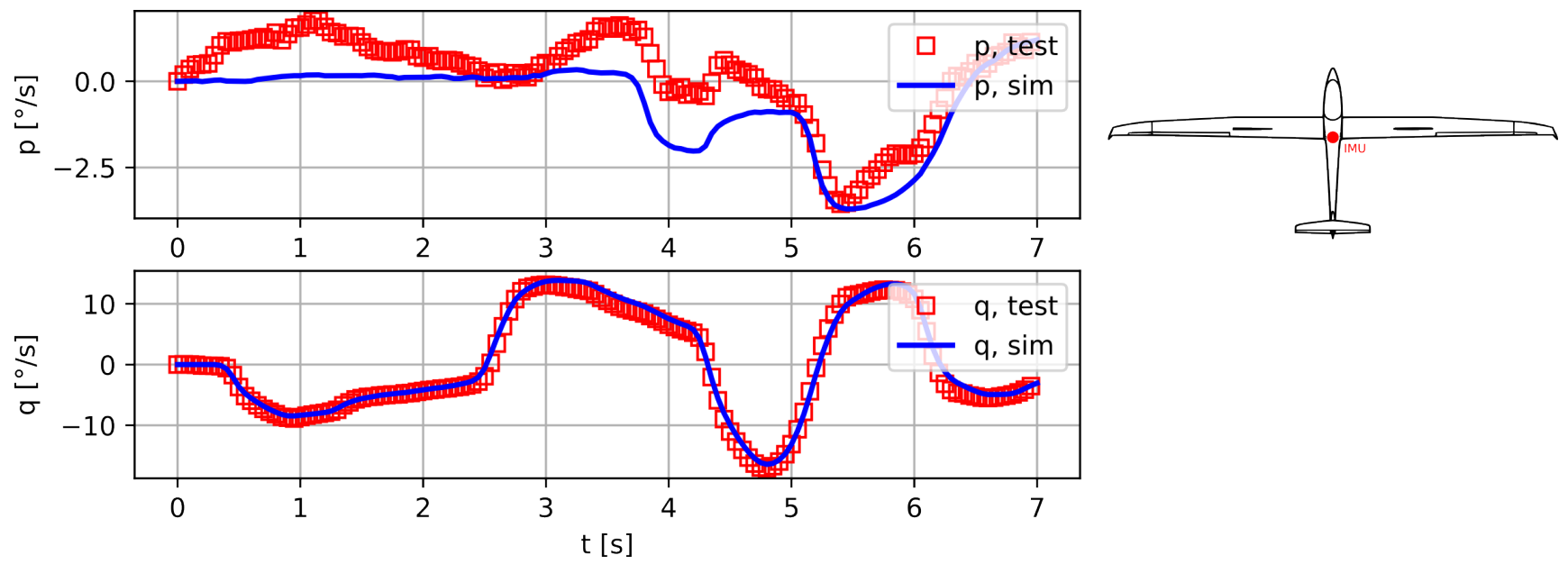

Fig. 11 Comparison of pitch rate $q$ and roll rate $p$

seconds are captured well.

Another objective of this study is to asses the need of structural dynamics and unsteady aerodynamics. As an example, the right wing root shear force is analyzed in more detail. In Figure 16 on the left, the shear force due to aerodynamic force $F_{z \text {,aero }}$ is plotted with green squares while the inertia force $F_{\mathrm{z} \text {,iner }}$ is plotted with cyan crosses. The sum of both leads to the total force $F_{\text {z,total }}$, plotted with blue dots. This line corresponds to the blue line shown previously in Figure 12. With red triangles the unsteady aerodynamic force $F_{\mathrm{z} \text {,unsteady }}$ and with black stars the aerodynamic force due to structural flexibility $F_{z \text {,flexible }}$ are plotted. One can see that both are small compared to the total force with blue dots. In Figure 16 on the right, the individual forces are scaled by the total force $F_{z \text {,total }}$. In this way one can see that both the unsteady aerodynamic force and the aerodynamic force due to structural flexibility have a contribution of $<10 \%$ to the total force. The peak at 5.0 seconds should be disregarded as the total force is very small.

\subsection{Rolling Maneuvers}

During the rolling maneuver, the aircraft also experiences a lateral and a longitudinal motion. In addition, a roll-yaw-coupling is expected. The roll-yawcoupling should be accounted for by the modeling of the induced drag, described in Section 3. The combination of rotations and translations should be handled by the non-linear equations of motion, described in Section 4. For the rolling maneuvers, the pilot used all three control commands $\xi, \eta$ and $\zeta$. Therefore, they should be applied in the time simulation as well. However, the 

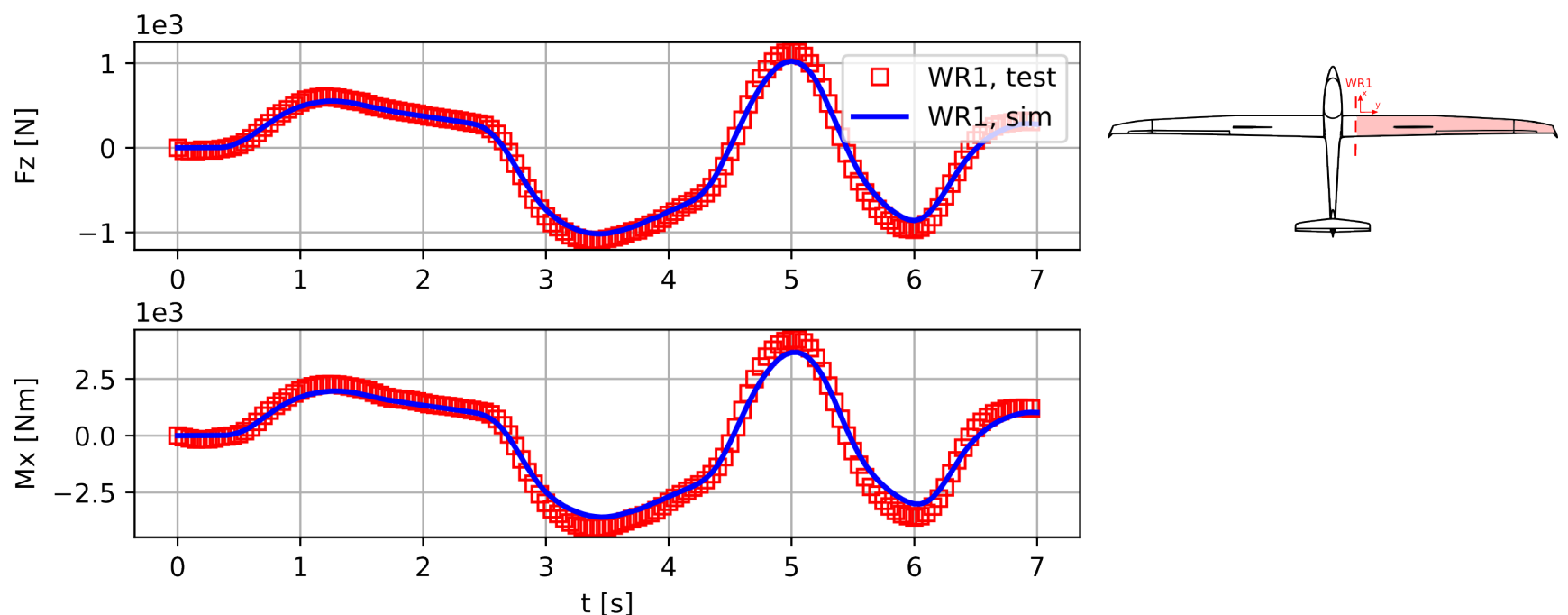

Fig. 12 Comparison of right wing root shear force $F_{\mathrm{z}}$ and bending moment $M_{\mathrm{x}}$
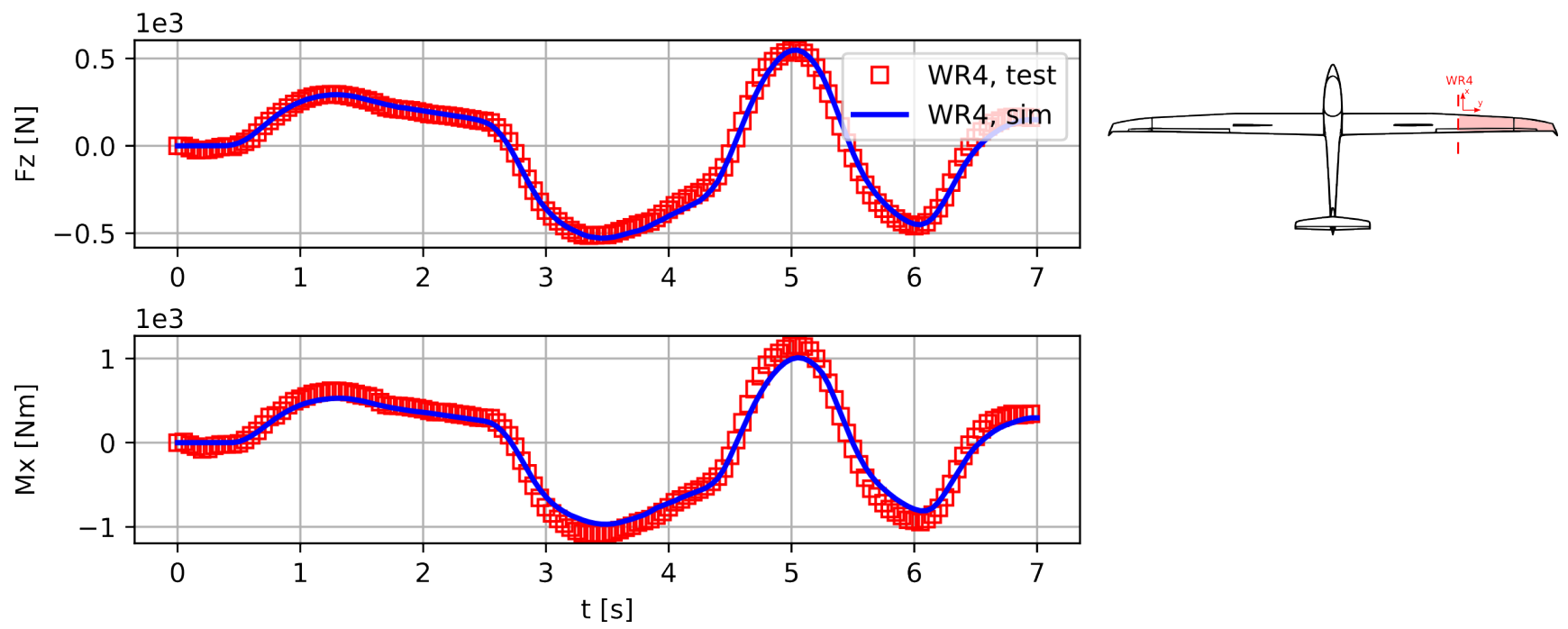

Fig. 13 Comparison of right outer wing shear force $F_{\mathrm{z}}$ and bending moment $M_{\mathrm{x}}$
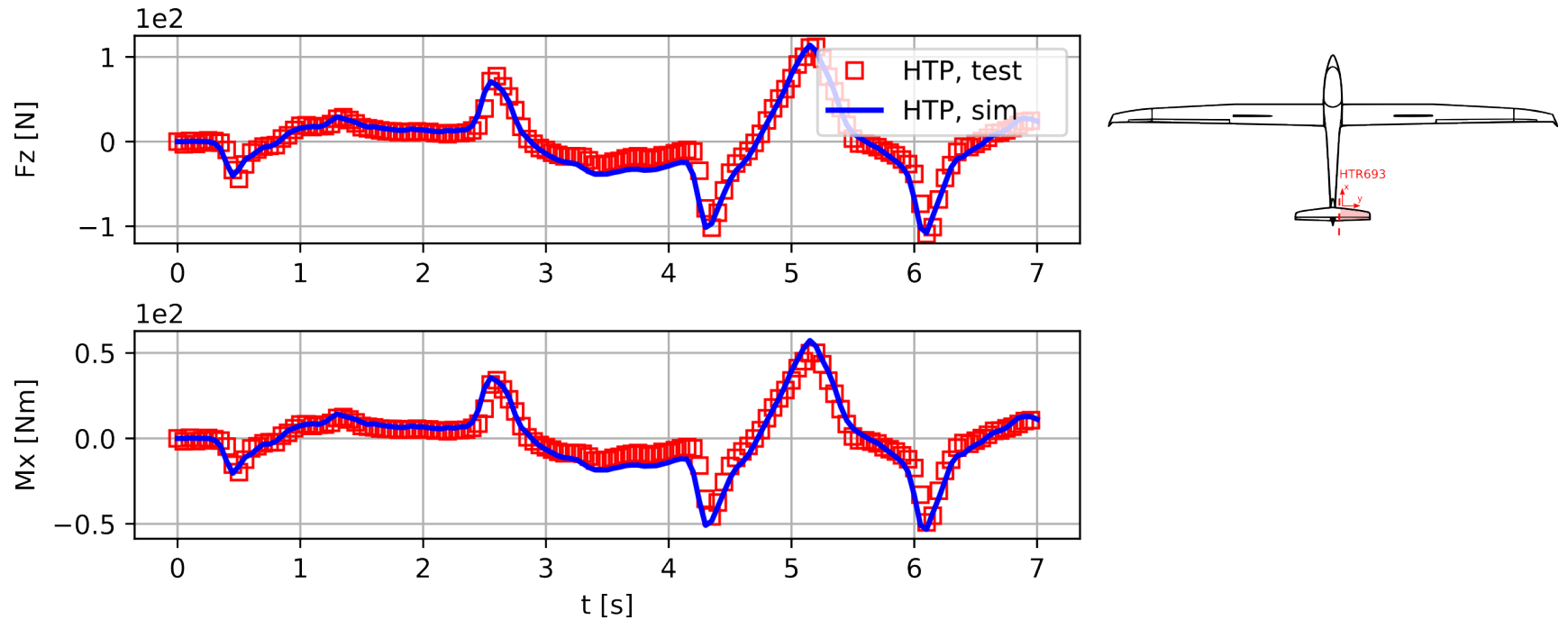

Fig. 14 Comparison of horizontal tail plane shear force $F_{\mathrm{z}}$ and bending moment $M_{\mathrm{x}}$ 


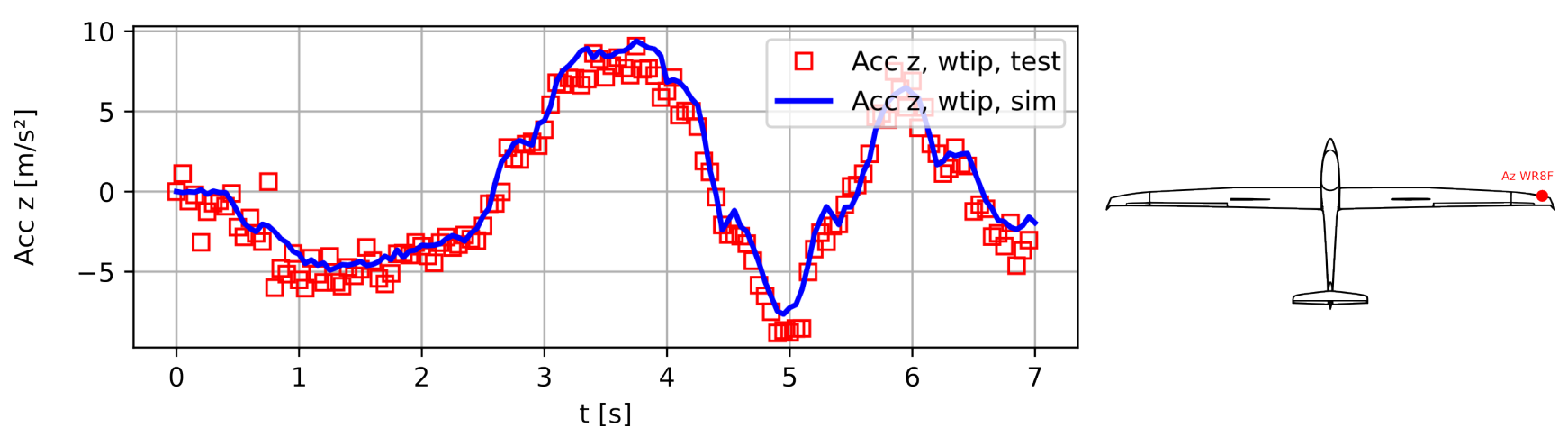

Fig. 15 Comparison of right wing tip acceleration in $z$ direction
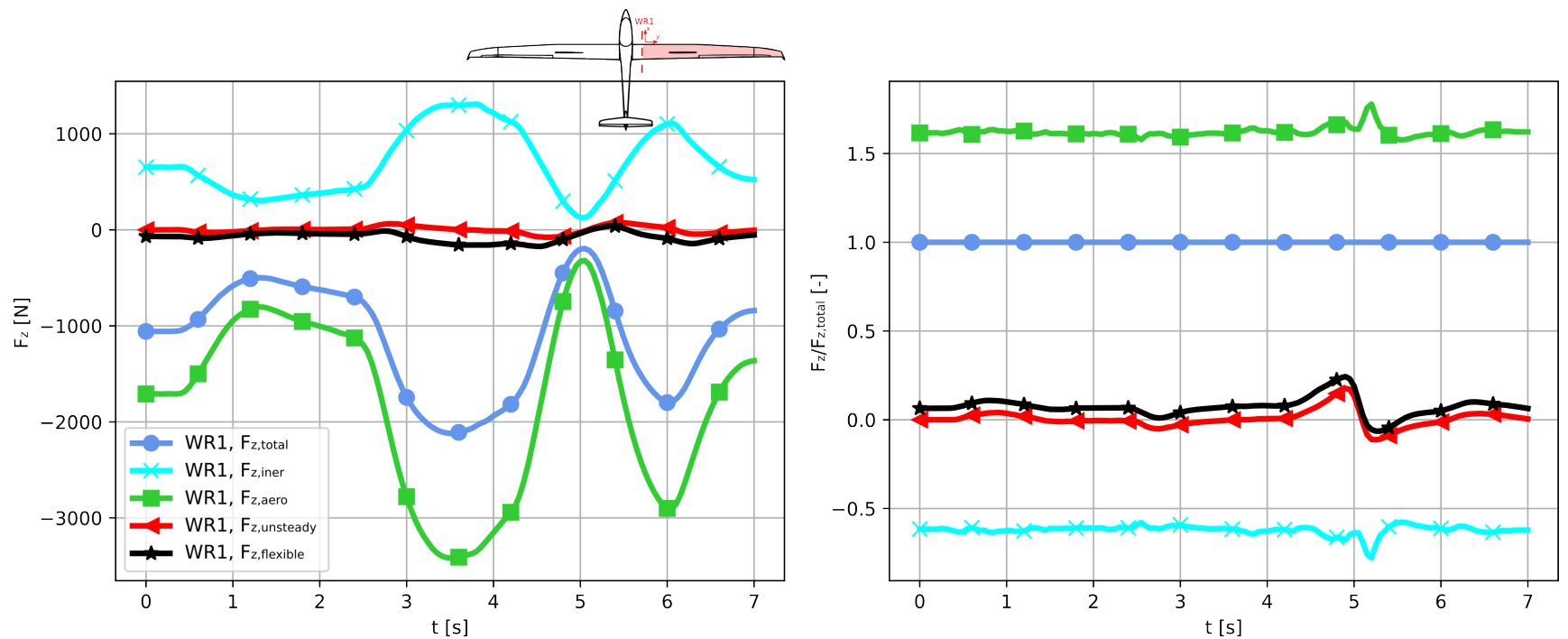

Fig. 16 Force contributions to the right wing root shear forces $F_{\mathrm{z}}$ in detail

introduction of the control command $\zeta$ is difficult as the fuselage is not modeled aerodynamically. A closer investigation yields that the simulation model is much more stable in lateral direction than the real sailplane. This is because the fuselage has a destabilizing effect. As described in Section 3, coefficients for the pitching moment due to the angle of attack $d C m / d \alpha$ and the yawing moment due to sideslip $d C n / d \beta$ have been added in an attempt to compensate this shortcoming. Still, the aircraft rotation about the $z$ axis is not captured precisely. This has to be taken into account in the analysis of the results. The rigid body motion of the rolling maneuvers are compared using the acceleration in $x, y$ and $z$ direction, the bank angle $\Phi$ and the roll rate $p$. These data are shown in Figures 17, 18 and 19 respectively. The agreement of the results is not as good as for the longitudinal maneuvers, but still acceptable. In addition to the rolling motion, there is also a lateral and longitudinal component. Therefore, in Figure 19 the pitch and yaw rates $q$ and $r$ are shown as well. For the yaw rate $r$, there is a good agreement, indicating the roll-yaw-coupling is captured adequately.
However, there is a disagreement for the pitch rate $q$, especially between 3.0 and 5.0 seconds. This deviation is also visible in the acceleration in $z$ direction. This is surprising, because for the longitudinal maneuvers shown in the previous section, the agreement was much better. Therefore, atmospheric turbulence are a plausible explanation. Looking at the section loads at the right wing root in Figure 20, both the shear forces $F_{\mathrm{z}}$ and the bending moments $M_{\mathrm{x}}$ show a very good agreement with the flight test. Again, one can see a slight deviation between 3.0 and 5.0 seconds. This is as expected, because the deviation of the pitch rate $q$ in Figure 19 leads to a temporarily higher angle of attack at the wing, causing higher loads.

\subsection{Aileron Sweep Maneuvers}

Both the longitudinal and the rolling maneuvers presented in the previous sections are dominated by large rigid body motions. Now, maneuvers with small and short aileron deflections with increasing frequency 

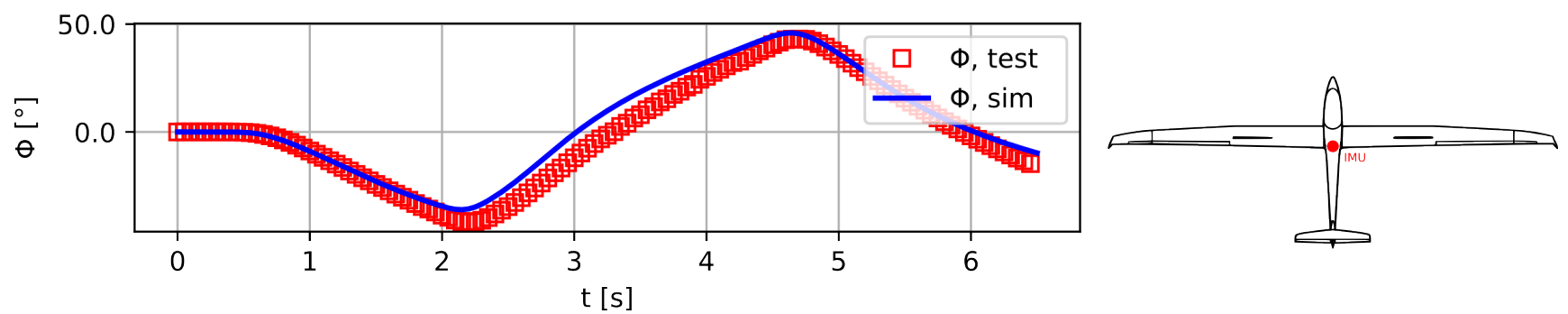

Fig. 17 Comparison of bank angle $\Phi$
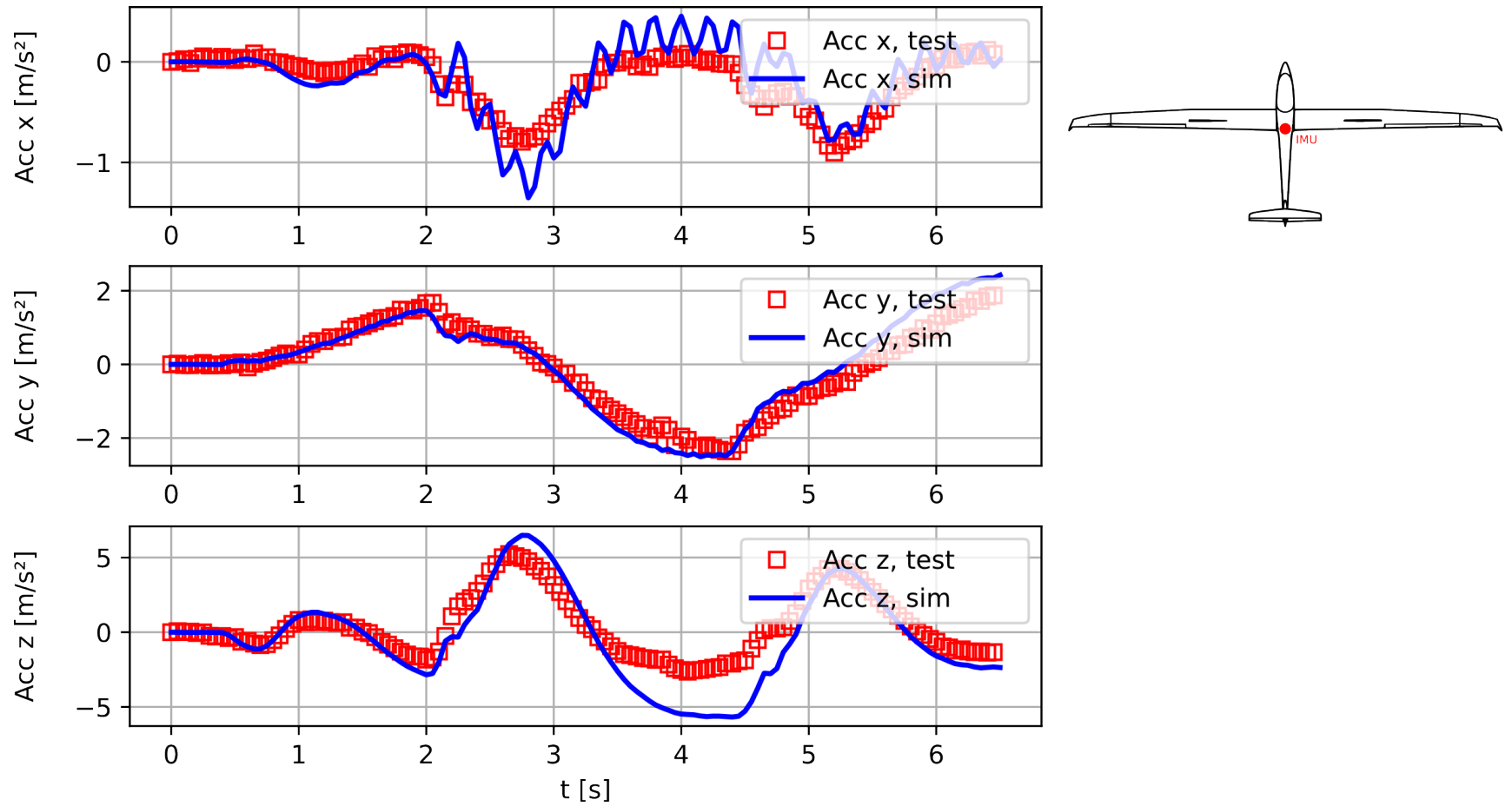

Fig. 18 Comparison of rigid body accelerations in $x, y$ and $z$ direction

are investigated. The rigid body motions are expected to be much smaller and structural flexibility is expected to become better visible. In addition, the highest command frequency corresponds to a reduced frequency of $k_{\text {red }} \approx 0.15$. Therefore, moderate unsteady effect can be expected.

For aileron sweep maneuver, only small aileron commands $\xi$ are used. Therefore, the magnitudes of the resulting loads are rather low and not suitable for a comparison. Instead, the accelerometers installed along the wing provide very good data for comparison. Figure 21 shows the acceleration in $z$ direction of the right wing tip. The agreement between flight test data and simulation is very good. With that basis, the aileron sweep is studied more closely.

Figure 22 shows the deflection and torsion of the wings due to structural flexibility. The time history of the commanded aileron deflection $\xi$ is given in the upper plot. The current time step is marked with a red dot and the corresponding wing deflection and torsion are given by the black squares in the plots below. In the current time step, the commanded aileron deflection $\xi$ is $\approx+4^{\circ}$, corresponding to a positive, clock wise direction of roll. The right wing aileron is deflected upwards, producing a positive, nose-up pitching moment and thus increasing the wing torsion $U_{\text {flex,ry }}$. The left wing aileron is deflected downwards, resulting in a negative, nose-down pitching moment and thus decreasing the wing torsion $U_{\text {flex,ry }}$. Note that the deflection of the wing is lagging behind slightly and is at this time step still close to the initial condition. The orange line and the dashed blue line indicate the maximum and minimum amplitudes of deflection and torsion during the maneuver. At the wing tip, the maximum and minimum deflection $U_{\text {flex,z }}$ is about $\pm 0.08 m$ with an initial wing tip deflection of $\approx 0.3 \mathrm{~m}$. The initial torsion $U_{\text {flex,ry }}$ of the wing tip is $\approx 0.34^{\circ}$. Measuring from 

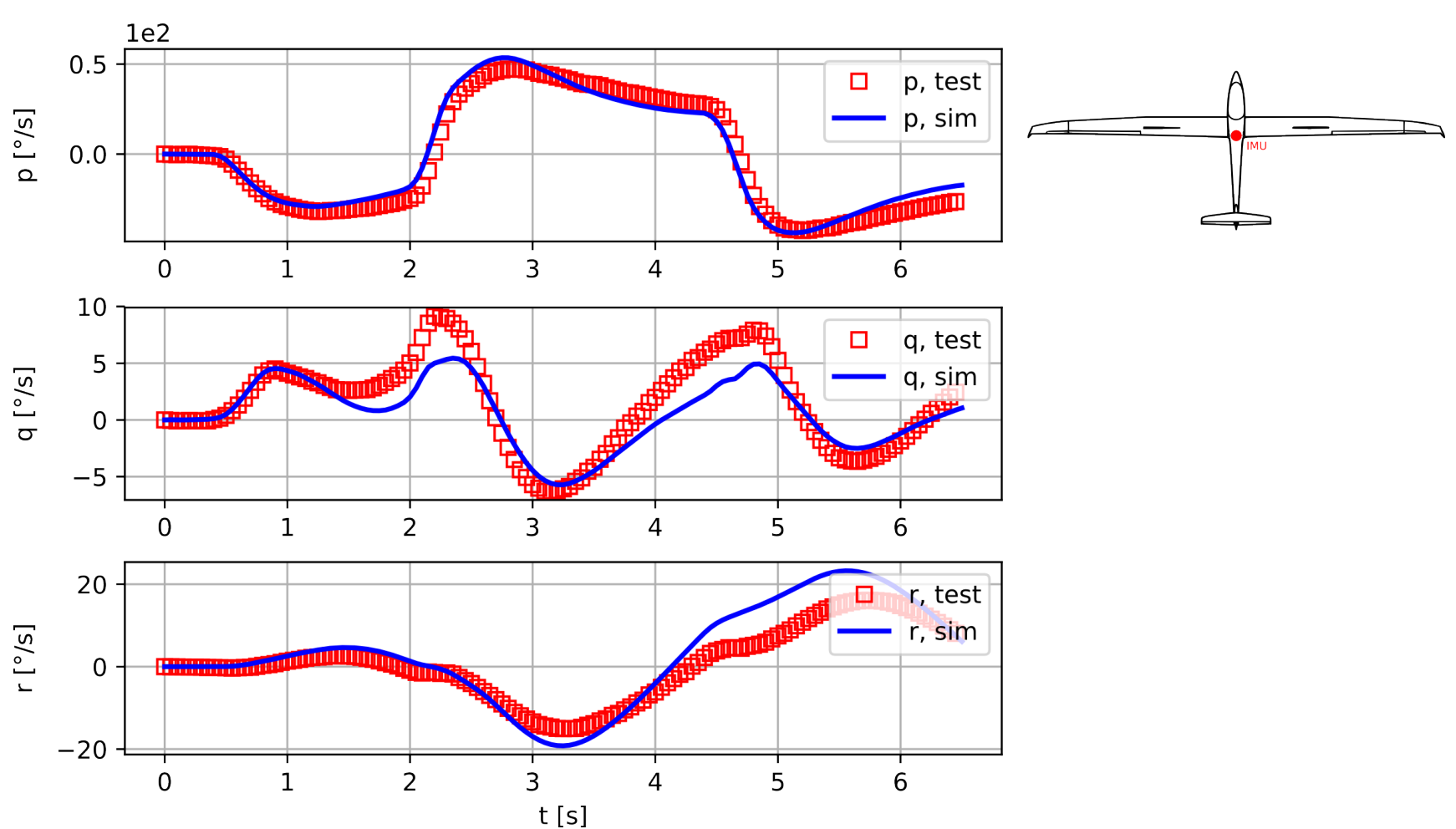

Fig. 19 Comparison of roll, pitch and yaw rates $p, q, r$
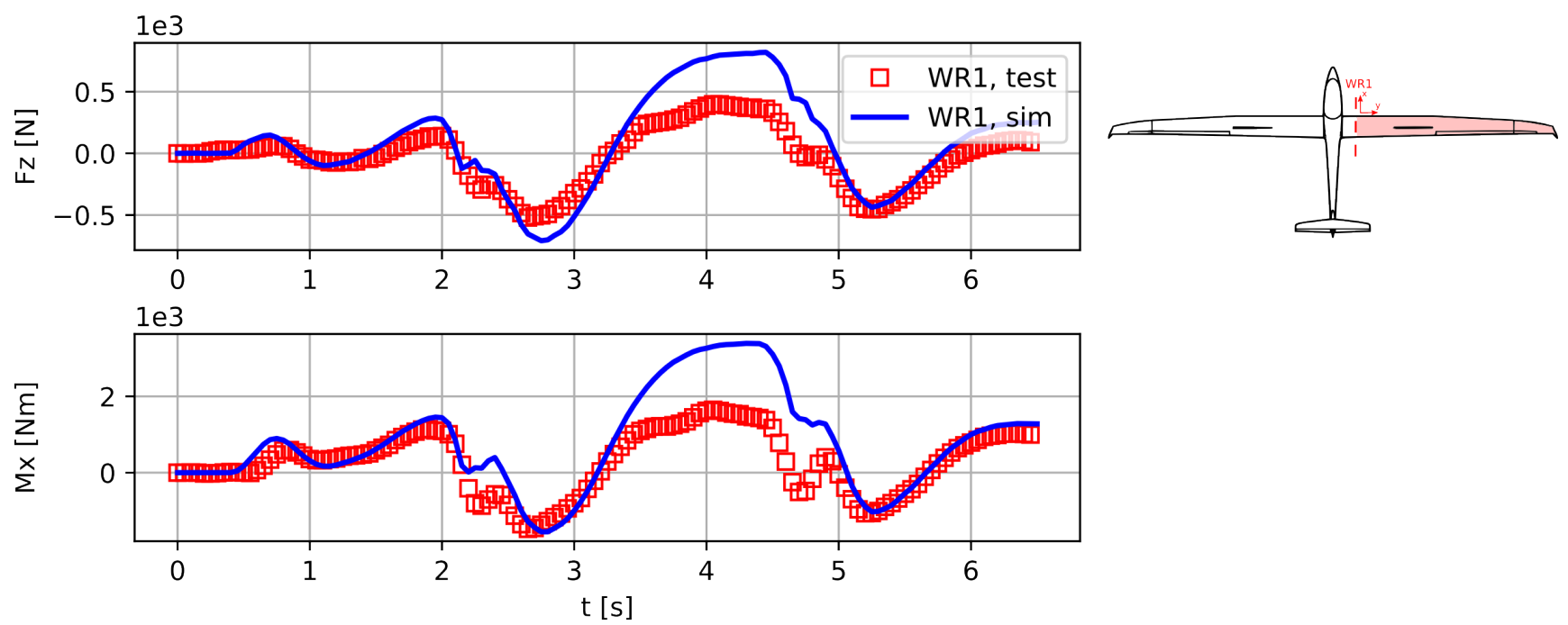

Fig. 20 Comparison of right wing root shear forces $F_{\mathrm{z}}$ and bending moments $M_{\mathrm{x}}$

that condition, the maximum torsion is $+0.13^{\circ}$ and the minimum torsion is only $-0.06^{\circ}$. This asymmetric behavior can be explained by the asymmetric aileron deflections. The downward deflection of the ailerons is usually lower than the upward deflection to avoid wing tip stall.

As for the longitudinal maneuvers, the need of structural dynamics and unsteady aerodynamics is assessed again in Figure 23 for the aileron sweeps.
This time, the outer wing shear force is analyzed. Using the same coloring as before, the shear force due to aerodynamic force $F_{\mathrm{z} \text {,aero }}$ is plotted with green squares while the inertia force $F_{\mathrm{z} \text {,iner }}$ is plotted with cyan crosses. The sum of both leads to the total force $F_{\text {z,total }}$, plotted with blue dots. With red triangles the unsteady aerodynamic force $F_{\text {z, unsteady }}$ and with black stars the aerodynamic force due to structural flexibility $F_{\mathrm{z} \text {,flexible }}$ are plotted. The aerodynamic force due to structural flexibility $F_{\mathrm{z} \text {,flexible shows an oscillating }}$ 


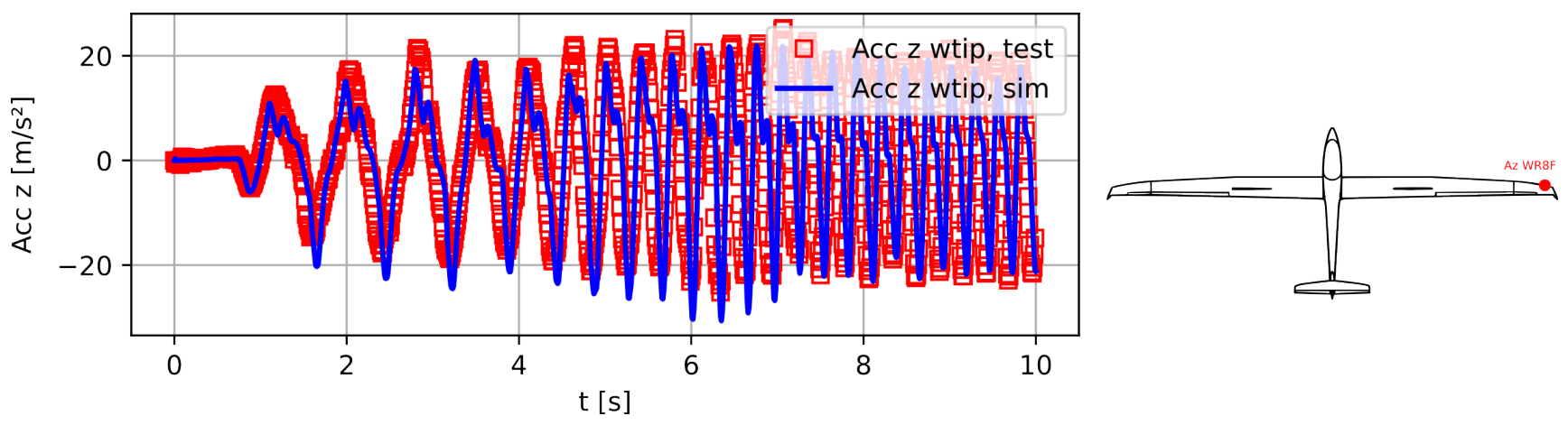

Fig. 21 Comparison of right wing tip acceleration in $z$ direction
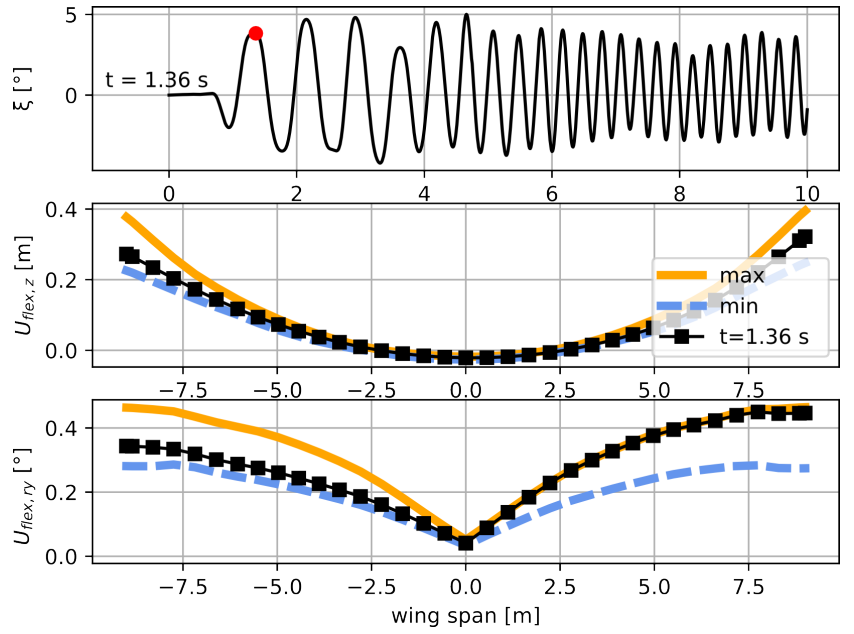

Fig. 22 Wing deflection $U_{\text {flex,z }}$ and torsion $U_{\text {flex,ry }}$ over wing span due to an aileron sweep

behavior with larger amplitudes at the beginning of the maneuver. As the aileron command frequency is increased, the amplitude decreases. In contrast, the unsteady aerodynamic force $F_{z \text {,unsteady shows a small }}$ amplitude at the beginning and increase towards the end where the command frequency becomes higher. In Figure 24 only the last second of the aileron sweep is shown. One can see clearly the lagging behavior of the unsteady aerodynamic forces $F_{\mathrm{z} \text {,unsteady }}$ in comparison to the total aerodynamic forces. Note that the unsteady aerodynamic forces are already included in the total aerodynamic forces $F_{z \text {,total }}$, indicating that the phase shift between steady and unsteady aerodynamics is even slightly bigger that visible from this plot. The plot shows that for this maneuver, unsteady aerodynamics account for up to $\pm 13 \%$ of the outer wing shear force $F_{\text {z,total }}$.

Finally, the effect of a reduced control surface efficiency of the ailerons is studied. This is sometimes necessary to account for effects of viscosity and thickness, which are not captured by the VLM and
DLM, see e.g. Ref. [33]. Figure 25 shows the roll rate $p$ with an aileron efficiency of 1.0 with a blue line and 0.7 with a dashed green line. The roll rate with an aileron efficiency of 1.0 shows a good agreement with the flight test while the roll rate with an aileron efficiency of 0.7 is too low. The XFOIL program developed by Drela [12] allows for the viscous and inviscid analysis of an airfoil. A short analysis of a typical sailplane airfoil suggests an aileron efficiency of 0.90 to 0.95 , depending on the angle of attack and the direction of deflection.

\section{Conclusion and Outlook}

In this work, a comparison of dynamic maneuver loads for the Discus-2c sailplane obtained from simulation and flight test is presented. The stiffness and mass models are set-up using simplified formulations derived from the preliminary design for the replication of an existing sailplane. The selected methods and resulting mass, stiffness, aerodynamic models have proven to be appropriate for dynamic maneuver loads analyses. In a next step, the loads process is tested with two longitudinal maneuvers with elevator deflections, two rolling maneuvers with aileron deflections and three aileron sweeps. The resulting rigid body motion, section forces and structural accelerations are compared to the data obtained from flight test. The dynamic increments of the longitudinal maneuvers show a very good agreement while the rolling maneuvers turned out to be more difficult and show an acceptable agreement. The results could be improved significantly in comparison to [54]. The aileron sweeps show a very good agreement and the influence of structural dynamics and unsteady aerodynamics is pointed out. The simulation is validated against flight test for the selected maneuvers successfully.

In the future, the structural and mass models could be improved. For the torsional moment $M_{\mathrm{y}}$, the 

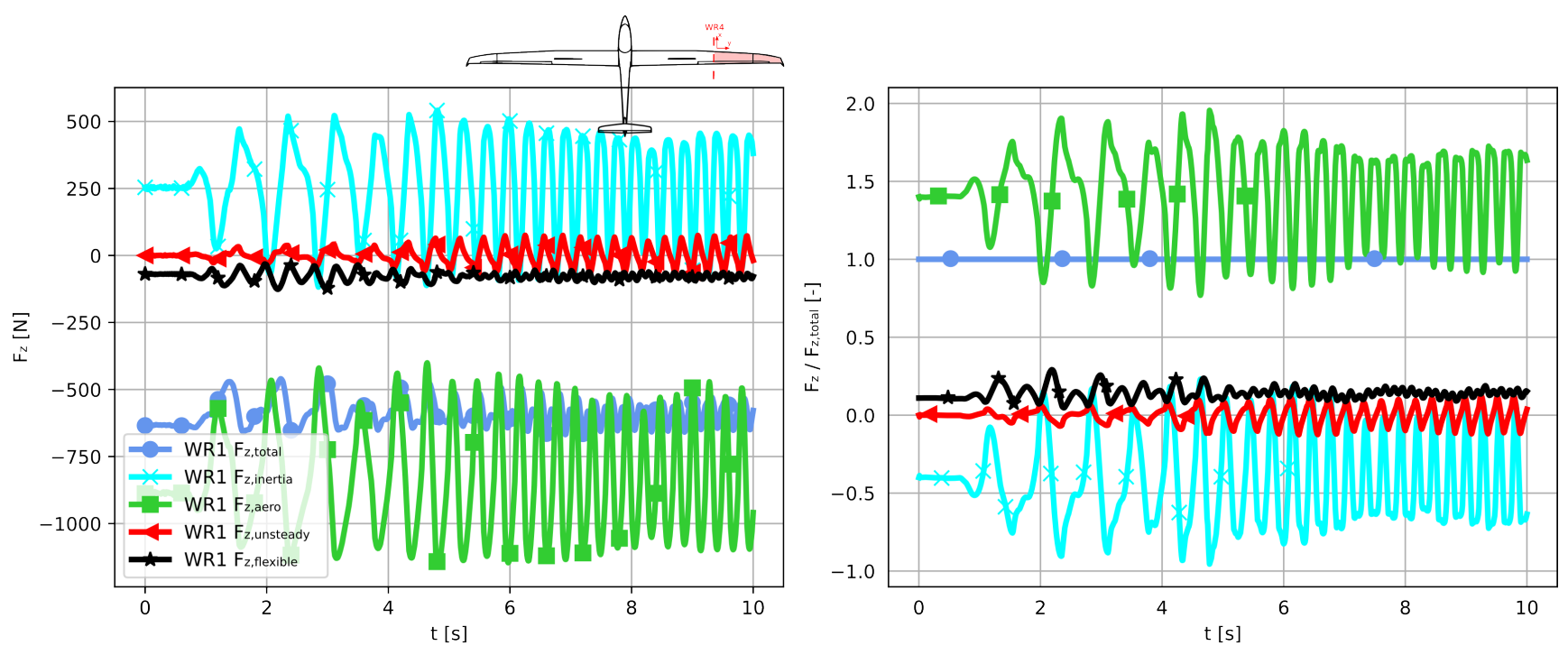

Fig. 23 Force contributions to the right outer wing shear forces $F_{\mathrm{z}}$ in detail

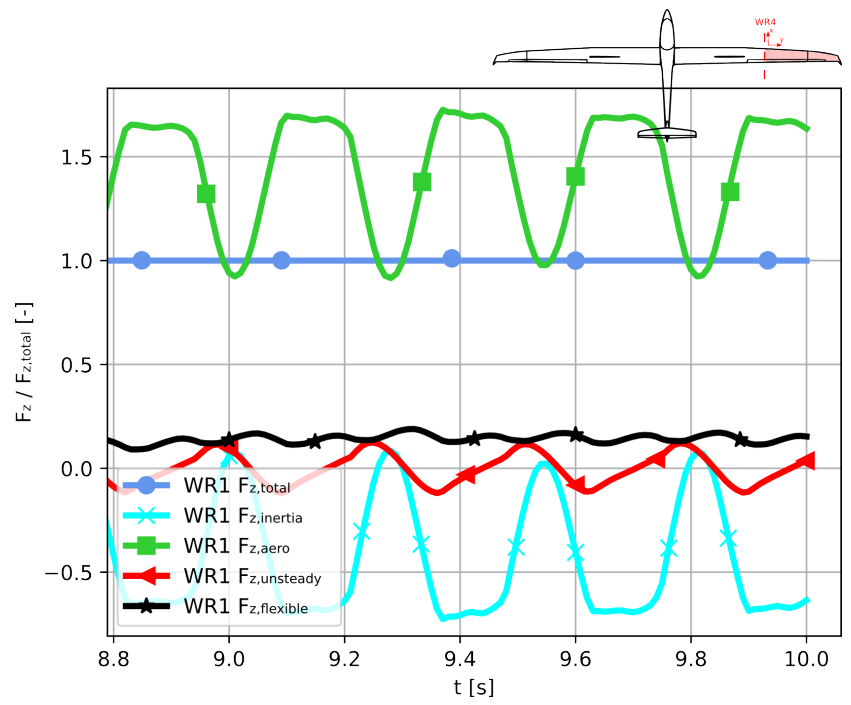

Fig. 24 Force contributions to the right outer wing shear forces $F_{\mathrm{z}}$ in detail, zoomed in

simulation sometimes did not match the measurement data. This was the case e.g. at the wing root. One presumption is that the measurement of $M_{\mathrm{y}}$ is difficult because the monitoring station is in close proximity the the fuselage, which might have an influence. In addition, $M_{\mathrm{y}}$ is usually very sensitive and small modifications in the structural or mass model might have a large impact. A better knowledge of the actual structure and mass distributions in chord wise direction would help to improve the models. However, a detailed model would mean to abandon the approach of using simple preliminary design methods.
Acknowledgements The authors would like to thank their colleague Gabriel P. Chiozzotto for providing the aeroelastic models and for valuable discussions.

\section{References}

1. Discus-2c

DLR. http://www.dlr.de/dlr/en/desktopdefault.aspx/ tabid-10203/339_read-9181/ \#/gallery/8791

2. DLR's research aircraft. http://www.dlr.de/dlr/en/ desktopdefault.aspx/tabid-10203/

3. Albano, E., Rodden, W.P.: A Doublet Lattice Method For Calculating Lift Distributions on Oscillation Surfaces in Subsonic Flows. In: AIAA 6th Aerospace Sciences Meeting. New York (22-24 January 1968)

4. Bisplinghoff, R., Ashley, H.: Principles of Aeroelasticity. Dover Books on Aeronautical Engineering. Dover Publications (2002). 00892 Unabridged, corrected republication of the edition published by John Wiley and Sons, Inc., New York, 1962.

5. Blair, M.: A Compilation of the Mathematics Leading to The Doublet Lattice Method. Technical Report WL-TR92-3028, Airforce Wright Laboratory, Ohio (1992)

6. Brown, P.N., Byrne, G.D., Hindmarsh, A.C.: VODE: A Variable-Coefficient ODE Solver. SIAM Journal on Scientific and Statistical Computing 10(5), 1038-1051 (1989). DOI 10.1137/0910062

7. Buttrill, C., Zeiler, T., Arbuckle, P.: Nonlinear simulation of a flexible aircraft in maneuvering flight. American Institute of Aeronautics and Astronautics (1987). DOI 10.2514/6.1987-2501. 00043

8. Claverias, S., Cerezo, J., Torralba, M., Reyes, M., Climent, H., Karpel, M.: Wake Vortex Encounter Loads Numerical Simulation. In: International Forum for Aeroelasticity and Structural Dynamics. Bristol, United Kingdom (2013)

9. Climent, H., Lindenau, O., Claverias, S., Viana, J., Oliver, M., Benitez, L., Pfeifer, D., Jenaro-Rabadan, G.: Flight Test Validation of Wake Vortex Encounter Loads. In: International Forum for Aeroelasticity and Structural Dynamics. Bristol, United Kingdom (2013) 

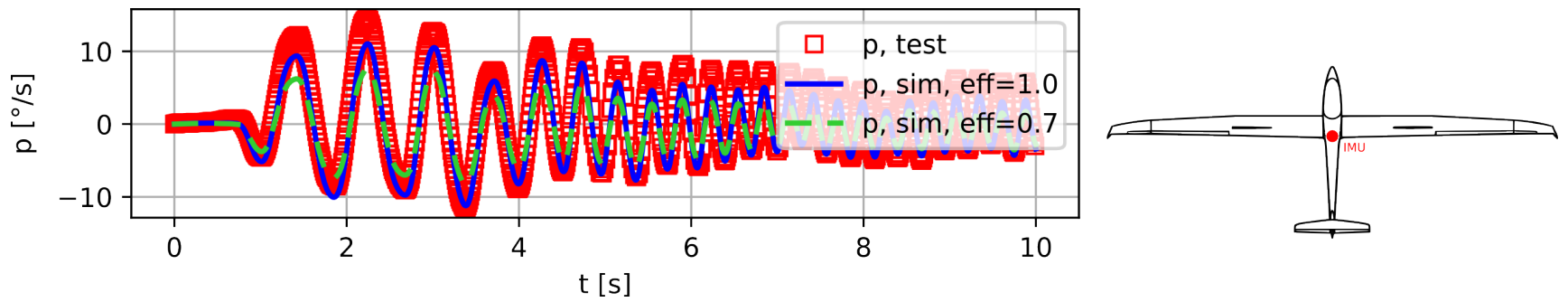

Fig. 25 Comparison of roll rates $p$ for different aileron efficiency

10. Cumnuantip, S., Kier, T., Pinho Chiozzotto, G.: Methods for the Quantification of Aircraft Loads in DLR-Project iLOADS. In: Deutscher Luft- Und Raumfahrtkongress (13. - 15. September 2016)

11. Dormand, J., Prince, P.: A family of embedded RungeKutta formulae. Journal of Computational and Applied Mathematics 6(1), 19-26 (1980). DOI 10.1016/0771050X(80)90013-3

12. Drela, M.: XFOIL Subsonic Airfoil Development System. http://web.mit.edu/drela/Public/web/xfoil/

13. Eller, D.: On an efficient method for time-domain computational aeroelasticity. Dissertation, KTH Royal Institute of Technology, Stockholm (2005)

14. Eller, D., Ringertz, U.: Aeroelastic Simulations of a Sailplane. Tech. rep., Department of Aeronautical and Vehicle Engineering, KTH (2005)

15. Garbow, B.S., Hillstrom, K.E., More, J.J.: Minpack/hybrd.html. https://www.math.utah.edu/ software/minpack/minpack/hybrd.html (1980)

16. Gupta, K.K., Brenner, M.J., Voelker, L.S.: Developement of an Integrated Aeroservoelastic Analysis Program and Correlation With Test Data. Technical Paper NASA Technical Paper 3120, Dryden Flight Research Facility, Edwards, California (1991). 00000

17. Handojo, V., Klimmek, T.: Böenlastanalyse der vorwärts gepfeilten ALLEGRA-Konfiguration. In: Deutscher LuftUnd Raumfahrtkongress. Rostock (22-24 September 2015)

18. Hedman, S.G.: Vortex Lattice Method for Calculation of Quasi Steady State Loadings on Thin Elastic Wings in Subsonic Flow. Tech. Rep. FFA Report 105, FFA Flygtekniska Försöksanstalten, Stockholm, Sweden (1966)

19. Karpel, M., Strul, E.: Minimumstate unsteady aerodynamic approximations with flexible constraints. Journal of Aircraft 33(6), 1190-1196 (1996). DOI 10.2514/3.47074. 00035

20. Katz, J., Plotkin, A.: Low-Speed Aerodynamics: From Wing Theory to Panel Methods. McGraw-Hill series in aeronautical and aerospace engineering. McGraw-Hill, New York (1991). 00002

21. Kier, T., Looye, G.: Unifying Manoeuver and Gust Loads Analysis Models (2009)

22. Klimmek, T.: Parametric Set-Up of a Structural Model for FERMAT Configuration for Aeroelastic and Loads Analysis. Journal of Aeroelasticity and Structural Dynamics (2), 31-49 (2014). DOI 10.3293/asdj.2014.27

23. Klimmek, T., Ohme, P., Ciampa, Handojo, V.: Aircraft Loads - An Important Task from Pre-Design to Loads Flight Testing. In: Deutscher Luft- Und Raumfahrtkongress. Braunschweig (13. - 15. September 2016)

24. Kotikalpudi, A.: Body Freedom Flutter (BFF) Doublet Lattice Method (DLM). http://hdl.handle.net/11299/ 165566 (2014)
25. Kotikalpudi, A., Pfifer, H., Balas, G.J.: Unsteady Aerodynamics Modeling for a Flexible Unmanned Air Vehicle. In: AIAA Atmospheric Flight Mechanics Conference. American Institute of Aeronautics and Astronautics, Dallas, Texas (2015). DOI 10.2514/6.20152854

26. Krüger, W., Handojo, Klimmek, T.: Flight Loads Analysis and Measurements of External Stores on an Atmospheric Research Aircraft. In: 58th AIAA/ASCE/AHS/ASC Structures, Structural Dynamics, and Materials Conference. American Institute of Aeronautics and Astronautics, Grapevine, Texas (2017)

27. Krüger, W., Klimmek, T.: Definition of a Comprehensive Loads Process in the DLR Project iLOADS. In: Deutscher Luft- und Raumfahrtkongress. Braunschweig, Deutschland (2016)

28. Krüger, W., Klimmek, T., Liepelt, R., Schmidt, H., Waitz, S., Cumnuantip, S.: Design and aeroelastic assessment of a forward-swept wing aircraft. CEAS Aeronautical Journal 5(4), 419-433 (2014). DOI 10.1007/ s13272-014-0117-0

29. Liersch

C.M., Huber, K.C.: Conceptual Design and Aerodynamic Analyses of a Generic UCAV Configuration. In: American Institute of Aeronautics and Astronautics (ed.) 32nd AIAA Applied Aerodynamics Conference. Atlanta, GA (16-20 June 2014). DOI 10.2514/6.2014-2001

30. Montel, M., Thielecke, F.: Validation of a nonlinear observer implementation for empennage loads estimation. CEAS Aeronautical Journal 7(2), 299 313 (2016). DOI 10.1007/s13272-016-0190-7

31. Nicolai, L.M., Carichner, G.E.: Fundamentals of Aircraft and Airship Design: Volume I Aircraft Design. American Institute of Aeronautics and Astronautics, Reston, VA (2010). DOI 10.2514/4.867538

32. Ohme, P., Raab, C. Preisighe Viana, M.V.: Lastenmessung im Flugversuch und Entwicklung Echtzeitfähiger Simulationsmodelle. In: Deutscher Kongress Für Luft- Und Raumfahrt. Braunschweig (13.-15. September 2016)

33. Palacios, R., Climent, H., Karlsson, A., Winzell, B.: Assessment of Strategies for Correcting Linear Unsteady Aerodynamics Using CFD or Test Results. In: International Forum on Aeroelasticity and Structural Dynamics (2001)

34. Pinho Chiozzotto, G.: Wing weight estimation in conceptual design: A method for strut-braced wings considering static aeroelastic effects. CEAS Aeronautical Journal 7(3), 499-519 (2016). DOI 10.1007/s13272-0160204-5

35. Powell, M.J.: A hybrid method for nonlinear equations. Numerical methods for nonlinear algebraic equations $\mathbf{7}$, 87-114 (1970) 
36. Preisighe Viana, M.V.: Sensor calibration for calculation of loads on a flexible aircraft. In: 16th International Forum on Aeroelasticity and Structural Dynamics. Saint Petersburg, Russia (2015)

37. Preisighe Viana, M.V.: Multipoint Model for Flexible Aircraft Loads Monitoring in Real Time. Dissertation, TU Braunschweig, Braunschweig, Deutschland (2016)

38. Preisighe Viana, M.V.: Time-Domain System Identification of Rigid-Body Multipoint Loads Model. In: AIAA Atmospheric Flight Mechanics Conference. American Institute of Aeronautics and Astronautics, Washington, D.C. (2016). DOI 10.2514/6.2016-3706

39. Ramsey, H.D., Lewolt, J.G.: Design maneuver loads for an airplane with an active control system. In: 20th Structures, Structural Dynamics, and Materials Conference. American Institute of Aeronautics and Astronautics, St. Louis, USA (1979)

40. Reschke: Integrated Flight Loads Modelling and Analysis for Flexible Transport Aircraft. Dissertation, Universität Stuttgart, Oberpfaffenhofen, Germany (2006)

41. Rodden, W., MacNeal, Harder, R., McLean, Bellinger, D.: MSC.Nastran Version 68 Aeroelastic Analysis User's Guide. MSC.Software Corporation (01/03/10)

42. Rodden, W.P., Giesing, J.P., Kálmán, T.P.: New Developments and Application of the Subsonic DoubletLattice Method for Nonplanar Configurations. AGARDCP-80-PT-2 - Symposium on Unsteady Aerodynamics for Aeroelastic Analyses of Interfering Surfaces (Part 2) (1971)

43. Roger, K.L.: Airplane Math Modeling Methods For Active Control Design. In: T.B. Company (ed.) AGARDCP-228 (1977)

44. Schlichting, H., Truckenbrodt, E.: Aerodynamik Des Flugzeuges: Aerodynamik Des Tragflügels (Teil 2), Des Rumpfes, Der Flügel-Rumpf-Anordnung Und Leitwerke, zweite neubearbeitete auflage edn. Springer-Verlag (1969)

45. Schrenk, O.: Ein einfaches Näherungsverfahren zur Ermittlung von Auftriebsverteilungen längs der Tragflügelspannweite. Tech. rep., Aerodynamische Versuchsanstalt (AVA), Göttingen, Germany (1940)

46. Sinske, J., Govers, Y., Handojo, V., Krüger, W.R.: HALO Flugtest mit instrumentierten Aussenlasten fuer Aeroelastik- und Lastmessungen im DLR Projekt iLOADS. In: Deutscher Luft- Und Raumfahrtkongress. Braunschweig (13. - 15. September 2016)

47. Skopinski, T.H., Aiken, W.S., Huston, W.B.: Calibration of strain-gage installations in aircraft structures for the measurement of flight loads. Technical Report NACATR-1178, National Advisory Committee for Aeronautics. Langley Aeronautical Lab, Langley Field, VA (1954)

48. Stauffer, W., Lewolt, J., Hoblit, F.: Application of advanced methods to the determination of design loads of the Lockheed L-1011 TriStar. American Institute of Aeronautics and Astronautics (1972). DOI 10.2514/ 6.1972- 775

49. Stauffer, W.A., Hoblit, F.M.: Dynamic gust, landing, and taxi loads determination in the design ofthe L1011. Journal of Aircraft 10(8), 459-467 (1973). DOI $10.2514 / 3.44383$

50. The Scipy community: Scipy.integrate.ode. http:// docs.scipy.org/doc/scipy/reference/generated/ scipy.integrate.ode.html \\#scipy.integrate.ode

51. The Scipy community: Scipy.optimize.fsolve. http:// docs.scipy.org/doc/scipy/reference/generated/ scipy.optimize.fsolve.html
52. Voß, A., Klimmek, T.: Maneuver Loads Calculation with Enhanced Aerodynamics for a UCAV Configuration. In: AIAA Modeling and Simulation Technologies Conference. American Institute of Aeronautics and Astronautics, Washington, D.C. (2016). DOI 10.2514/ 6.2016-3838

53. Voß, A., Klimmek, T.: Design and sizing of a parametric structural model for a UCAV configuration for loads and aeroelastic analysis. CEAS Aeronautical Journal 8(1), 67-77 (2017). DOI 10.1007/s13272-016-0223-2

54. Voß, A., Pinho Chiozzotto, G., Ohme, P.: Dynamic Maneuver Loads Calculation for a Sailplane and Comparison with Flight Test. In: IFASD 2017 - 17th International Forum on Aeroelasticity and Structural Dynamics. Como, Italy (25-28 June 2017)

55. Waszak, M., Buttrill, C., Schmidt, D.: Modeling and Model Simplification of Aeroelastic Vehicles: An Overview. Tech. Rep. NASA Technical Memorandum 107691, NASA Langley Research Center (1992)

56. Waszak, M.R., Schmidt, D.K.: Flight dynamics of aeroelastic vehicles. Journal of Aircraft 25(6), 563-571 (1988). DOI 10.2514/3.45623

57. ZONA Technology Inc.: ZAERO Theoretical Manual, vol. Version 9.0. Scottsdale, Arizona (2014) 